Check for updates

Cite this: RSC Adv., 2020, 10, 21662

\title{
Recent advances in the design of cathode materials for Li-ion batteries
}

\begin{abstract}
Nourhan Mohamed and Nageh K. Allam (D)*
The Li-ion battery (LIB) industry has rapidly developed and dominates the market of electric vehicles and portable electronic devices. Special attention is devoted to achieving higher power and energy densities, along with enhancing safety and reducing cost. Therefore, critical insights should be made on the understanding of the behavior of the components of LIBs under working conditions in order to direct future research and development. The present review discusses the literature on the properties and limitations of different cathode materials for LIBS, including layered transition metal oxides, spinels, and polyanionic positive electrode materials, with critical insights on the structural, thermal, and electrochemical changes that take place during cycling. Besides, the strategies and techniques capable of overcoming current limitations are highlighted.
\end{abstract}

Received 13th April 2020

Accepted 2nd June 2020

DOI: $10.1039 / \mathrm{dOra03314f}$

rsc.li/rsc-advances

At the global level, renewable sources show a great theoretical ability to cover the whole human need for energy. For instance, Earth receives $1.2 \times 10^{5} \mathrm{TW}$ of solar power, which can cover the annual worldwide need for energy in almost one hour. Despite the current limitations in the properties of materials that lead to inefficient collection and conversion of light, the primary current focus is on how to progress rapidly towards highly functional materials to satisfy the ever-increasing energy demand.

Energy storage technologies are divided into stationary and portable systems; both are of great importance, and each type is at a different stage of development. In multiple stationary applications, grid-connected energy storage systems have been

Energy Materials Laboratory, School of Sciences and Engineering, The American University in Cairo, New Cairo 11835, Egypt. E-mail: nageh.allam@aucegypt.edu

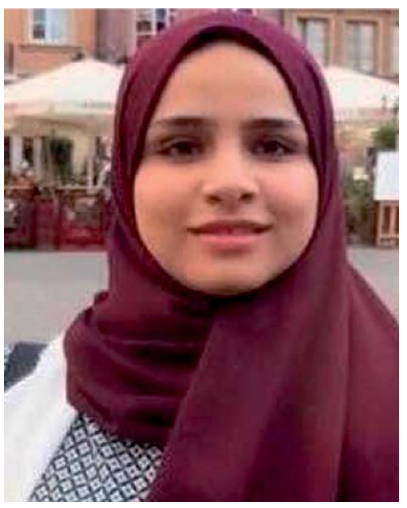

Nourhan Mohamed received her M.Sc. degree in Sciences, Technologies, Health from Picardie Jules Verne University. Her master's program was a joint Erasmus program in materials for energy storage and conversion "MESC". She joined the Energy Materials Laboratory at AUC for a year as a Research Assistant. Her research is focused on positive electrode materials for Li-ion batteries.

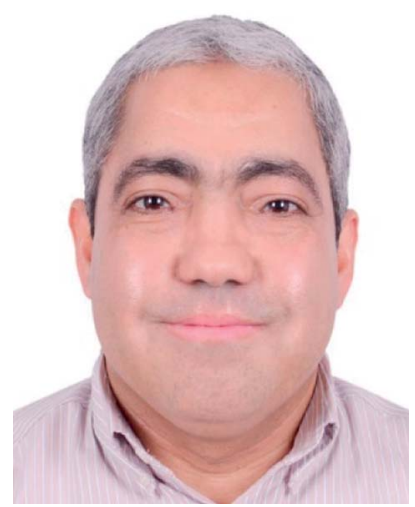

Nageh Allam received his $P h D$ in Materials Science and Engineering from The Pennsylvania State University. He joined Georgia Institute of Technology as a postdoctoral fellow then Massachusetts Institute of Technology as a Research Scholar. He moved to The American University in Cairo in September 2011 where he is now a professor of Materials Science and Engineering. His research focuses on the fabrication of well-designed nanostructured materials with composition, size, and shape control for use in energy conversion and storage, electrochemical sensors, and biomedical applications, among others. His research comprises both experimental and theoretical activities. 
deployed to facilitate the integration of renewable power sources due to their variable nature. Energy storage systems are connected to the grid to provide sustainability by storing energy during the low-energy demand time and supply it during the high-energy demand time. Nowadays, the global energy storage is dominated by one technology, the pumped hydropower, for grid applications, which accounts for $95 \%$ of the worldwide energy storage. The rest 5\% comprise mainly of thermal, mechanical, and electrochemical storage. In comparison, a project of Li-ion batteries contributes $24 \mathrm{MW}$ that is as low as $0.01 \%$ of the overall storage, as shown in Fig. 1 .

Advances in renewable energy require modernization of the electricity storage systems, including electrochemical capacitors, lead-acid batteries, high-temperature sodium batteries, lithium-ion batteries, and redox flow batteries. In this review, we focus mainly on Li-ion batteries because of their superior performance in comparison with other conventional battery types. Li-ion batteries dominate the portable devices industry due to their prime properties such as high-energy-density, high charge/discharge rate, low maintenance, and long-lifetime, which make them the most suitable candidates for a plethora of applications. Therefore, they met the market requirements, and their sales increased significantly between 2008 and 2014 from 0.1 to 22.5 billion dollars in the electric vehicles sector and from 9.1 to 31 billion dollars in the total market.,

Li-batteries have been widely adopted because $\mathrm{Li}$ is the lightest metal $\left(6.94 \mathrm{~g} \mathrm{~mol}^{-1}\right)$ with the smallest radius that can provide high gravimetric and volumetric capacity, leading to a significant weight and volume reduction of the battery. Furthermore, Li exhibits the lowest reduction potential $(-3.04 \mathrm{~V}$ versus $\mathrm{SHE}$ ), allowing the cell to deliver the highest possible potential resulting in a decrease in the number of cells required to operate a device. However, several safety problems caused the withdrawal of $\mathrm{Li}$ metal batteries from the market after some catastrophic accidents because of the high reactivity of the $\mathrm{Li}$ metal and the growth of $\mathrm{Li}$ dendrite, which results in short circuits. Therefore, Li metal anode was replaced by safer alternatives such as intercalation, alloying, and conversion materials. Consequently, much research has focused on the chemical, thermal, and structural stability of the materials for
Li-ion batteries and how to introduce practical solutions to their well-recognized safety problems. These problems are related to the reactions that can take place under extreme conditions such as high over-potential, electrolyte decomposition, SEI decomposition, cathode material decomposition, and generation of flammable gases. The safety stands as an obstacle to the introduction of new high energy cathode materials because they work outside the stability window of the available electrolytes. Improving the performance, along with the cost and safety, are the key factors to expand the Li-ion battery applications significantly. A significant interest in Li-ion batteries is given to the cathode materials and how to improve its electrochemical performance along with preserving the mechanical, electrochemical, and chemical stability of the materials upon cycling. Because the performance of the battery, including cell potential, energy density, power density, lifetime, and safety in addition to cost, depends to a great extent on the cathode material. For instance, high energy can be obtained from a battery by increasing the intercalation voltage (cathode material type) or the amount of $\mathrm{Li}^{+}$that can participate in the electrochemical reaction (capacity). In this review paper, we focus on different types of cathode materials and discuss their electrochemical properties considering their structure and morphology as well as thermal and electrochemical performance.

\section{Li-ion batteries (LIBs)}

A Li-ion module consists of several cells connected into packs to deliver the required voltage, power, and energy. LIBs convert chemical energy into electricity via a reversible electrochemical reaction. They consist mainly of anode and cathode, which are electronically isolated by an electrolyte. The anode is the negative electrode, which is oxidized during the electrochemical reaction to donating electrons to the external circuit. The cathode is the positive electrode, which is reduced during the electrochemical reaction and accepts electrons from the external circuit. The electrolyte is a solid or a liquid medium that allows the Li ions to move between the anode and cathode and force the electrons to move through the external circuit. Therefore, electrolyte should exhibit high ionic and low electronic conductivity. Moreover, the Fermi level of the anode

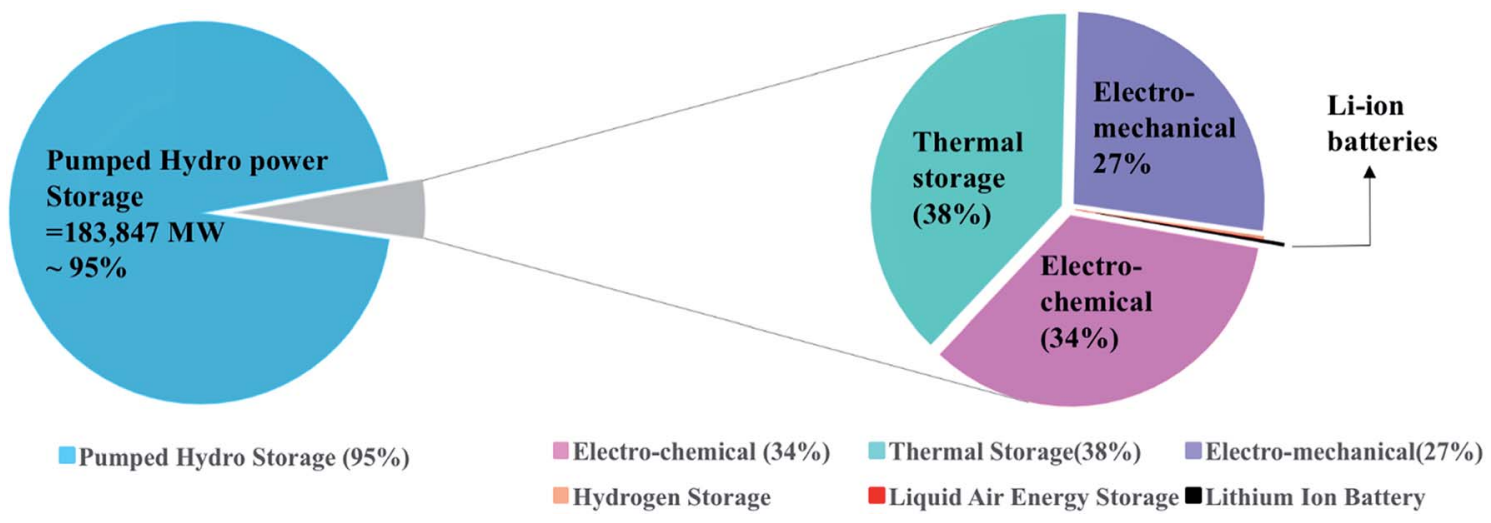

Fig. 1 Worldwide energy storage projects contribution to the grid applications. Data is extracted from US-DOE. ${ }^{3}$ 
should be at lower energy than the LUMO of the electrolyte to prevent the electrolyte reduction, while the Fermi level of the cathode should be at higher energy than the HUMO of the electrolyte to prevent the electrolyte oxidation. During the first charge, the electrolyte undergoes a reduction reaction at the surface of the anode forming an irreversible passive layer, known as solid electrolyte interphase (SEI). It is a complicated layer composed of organic and inorganic components that prevent the further decomposition of the electrolyte upon cycling, but it results in an irreversible capacity loss. The performance of the battery is dependent on the morphology, composition, and thickness of this layer. ${ }^{4}$ If this protective layer is damaged, the decomposition of the electrolyte will continue again, leading to fast heating and undesirable chemical reactions that are hazardous. There are several reported mechanisms for the formation and stabilization of the SEI on the surface of both anode and cathode..$^{5-8}$

\section{Challenges and trend in cathode materials for Li-ion batteries}

The development of the cathode materials for Li-ion batteries remains challenging because the existing materials such as layered transition metals oxides, olivines, or spinel all show upsides and downsides. For example, the layered oxides such as $\mathrm{LiCoO}_{2}$ suffers from the instability that limits their potential window and capacity. Moreover, the toxicity and the high production cost of the Co-based materials are undesirable. On the other hand, Li-rich layered oxides $\left(\mathrm{Li}_{1+x} \mathrm{M}_{1-x} \mathrm{O}_{2}\right)$, where $\mathrm{M}$ is a mixture of transition metals ( $\mathrm{Ni}, \mathrm{Mn}$, and $\mathrm{Co}$ ), is promising as they can work at high discharge voltages of $>4.5 \mathrm{~V}$ and deliver high specific capacities. However, they suffer from large voltage decay during cycling and high irreversible capacity loss at the first cycles, which limit their use. Moreover, olivine materials such as $\mathrm{LiFePO}_{4}$ are competitive candidates surpassing the stability of layered oxides at elevated temperatures due to their high thermal and structural stability. However, their low

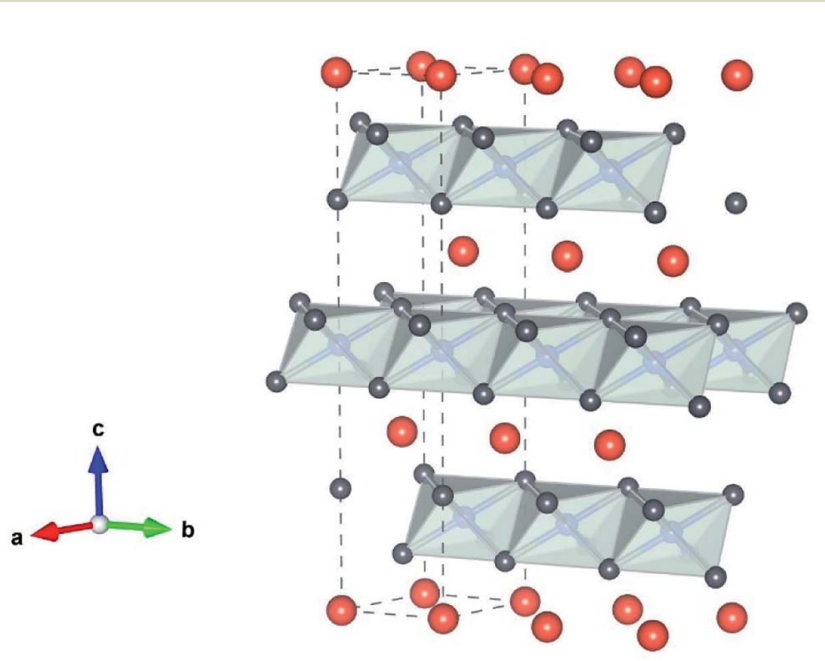

Fig. 2 The crystallographic framework of the layered $\mathrm{LiMO}_{2}(\mathrm{M}$ is $\mathrm{Co}$ or $\mathrm{Ni}$ ) consisting of $\mathrm{MO}_{6}$ octahedra (gray) and $\mathrm{Li}^{+}$(orange) "by VESTA".
Table 1 Cell parameters of $\mathrm{LiMO}_{2}$ ( $\mathrm{M}$ is $\mathrm{Co}$ or Ni)

\begin{tabular}{llllll}
\hline $\mathrm{LiMO}_{2}$ & $a(\AA)$ & $c(\AA)$ & $c / a$ & $V\left(\AA^{3}\right)$ & Ref. \\
\hline $\mathrm{LiCoO}_{2}$ & $2.8157(3)$ & $14.0517(3)$ & 4.99 & $96.48(3)$ & 9 \\
$\mathrm{LiNiO}_{2}$ & $2.8898(2)$ & $14.2212(2)$ & 4.92 & $102.85(6)$ &
\end{tabular}

electronic and ionic conductivity stand as an obstacle to expand their use for high energy Li-ion batteries. Several steps forward have been made in the development of cathode materials for Liion batteries to overcome current challenges. First, investigating the changes in the electrochemical performance inside the cathode during cycling will lead to understanding the origin of the malfunction of the materials under working conditions. The strategies considered to improve these materials should address the problems related to the electrochemical performance side by side with the safety and cost issues. These strategies mainly include designing nanostructured materials with controlled morphology, introducing artificial defects in the nanostructured materials, using nanostructured complexes by doping or surface coating, and surface modification that is indispensable to minimize the undesirable side reaction at the electrolyte-cathode interface. Those are critical factors in jeopardizing the electrode performance. Also, there is a great interest in identifying new cathode materials that can fulfill the required balance between the performance and environmental requirements. In this review, we compare the different cathode materials that have been widely used in Li-ion batteries and analyze their performance.

\section{Layered transition metal oxides positive electrode materials}

The reason for the continued attention to transition metal oxides $\mathrm{LiMO}_{2}(\mathrm{M}=\mathrm{Co}, \mathrm{Mn}, \mathrm{Ni})$ as electrode materials is their high $\mathrm{Li}^{+}$mobility in 2-dimensional space, thanks to its layered

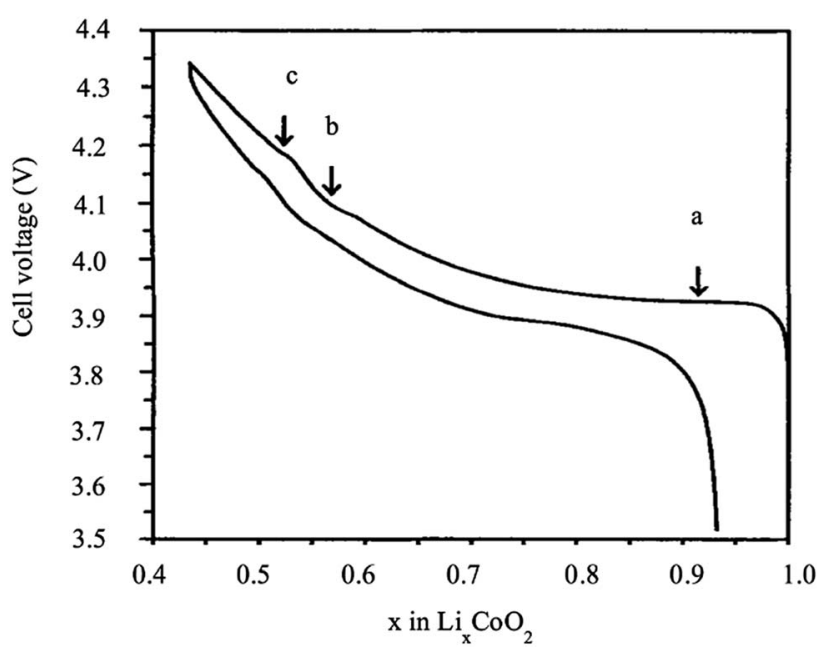

Fig. 3 Cell voltage of $\mathrm{Li}_{x} \mathrm{CoO}_{2}$ as a function of $x{ }^{12}$ 
structure, as shown in Fig. 2. The crystallographic framework of Layered $\mathrm{LiMO}_{2}$ (O3 type) is $\alpha-\mathrm{NaFeO}_{2}$-like structure, which consists of a cubic close-packed oxygen array occupying the $6 \mathrm{c}$ sites, where $\mathrm{Li}$ and $\mathrm{M}$ ions occupy the $3 \mathrm{a}$ and $3 \mathrm{~b}$ sites, respectively. $\mathrm{M}$ and $\mathrm{Li}$ ions occupy alternate layers in the octahedral sites along the (111) plane forming ABC stacking sequence. The cell parameters of $\mathrm{LiMO}_{2}(\mathrm{M}=\mathrm{Co}$ and Ni) are shown in Table 1.

\section{1 $\mathrm{LiCoO}_{2}$}

$\mathrm{LiCoO}_{2}$ represents a significant advance in the history of rechargeable Li-ion batteries, as it was the first commercialized positive electrode material by Sony in 1991. Sony combined the $\mathrm{LiCoO}_{2}$ cathode and carbon anode to produce the first successful rechargeable Li-ion battery. From the electrochemistry point of view, $\mathrm{Li}_{x} \mathrm{CoO}_{2}$ is a very attractive material because it exhibits a high theoretical capacity of $274 \mathrm{~mA} \mathrm{~h} \mathrm{~g}^{-1}$ and high energy density. However, its performance is strongly affected by structural and thermal instability at high voltage, and high temperature, as well as fast capacity, fade at the high current rate or deep cycling. During charging, several phase transitions take place at different stages of the de-intercalation of $\mathrm{Li}^{+}$. Fig. 3 shows a typical charge/discharge behavior of $\mathrm{Li}_{x} \mathrm{CoO}_{2}$ as a function of the amount of $x$. The large plateau at $3.93 \mathrm{Vvs} \mathrm{Li}^{+} /$ $\mathrm{Li}^{0}$ corresponds to a first-order transition ( $\left.\mathrm{H} 1 \leftrightarrow \mathrm{H} 2\right)$. The coexistence of two phases between the lithium concentrations $x$ $=0.75$ and 0.93 is accompanied by the transition from a semiconductor to the metal, which facilitates the charge transfer. In the $x$ range between 0.75 and 0.25 , two order/disorder transitions were observed from hexagonal to monoclinic, then from monoclinic to hexagonal, which correspond to the plateaus $b$ and $c$. Therefore, almost one-half of the lithium ions can be cycled reversibly in and out of the compound corresponding to the composition range between $x=1$ and 0.5 . Consequently, a practical specific capacity of $140 \mathrm{~mA} \mathrm{~h} \mathrm{~g}{ }^{-1}$ is obtained at a charging voltage of $4.2 \mathrm{~V} v s . \mathrm{Li}^{\prime} \mathrm{Li}^{+}$to avoid the structural rearrangement of the material. ${ }^{\mathbf{1 0 , 1 1}}$
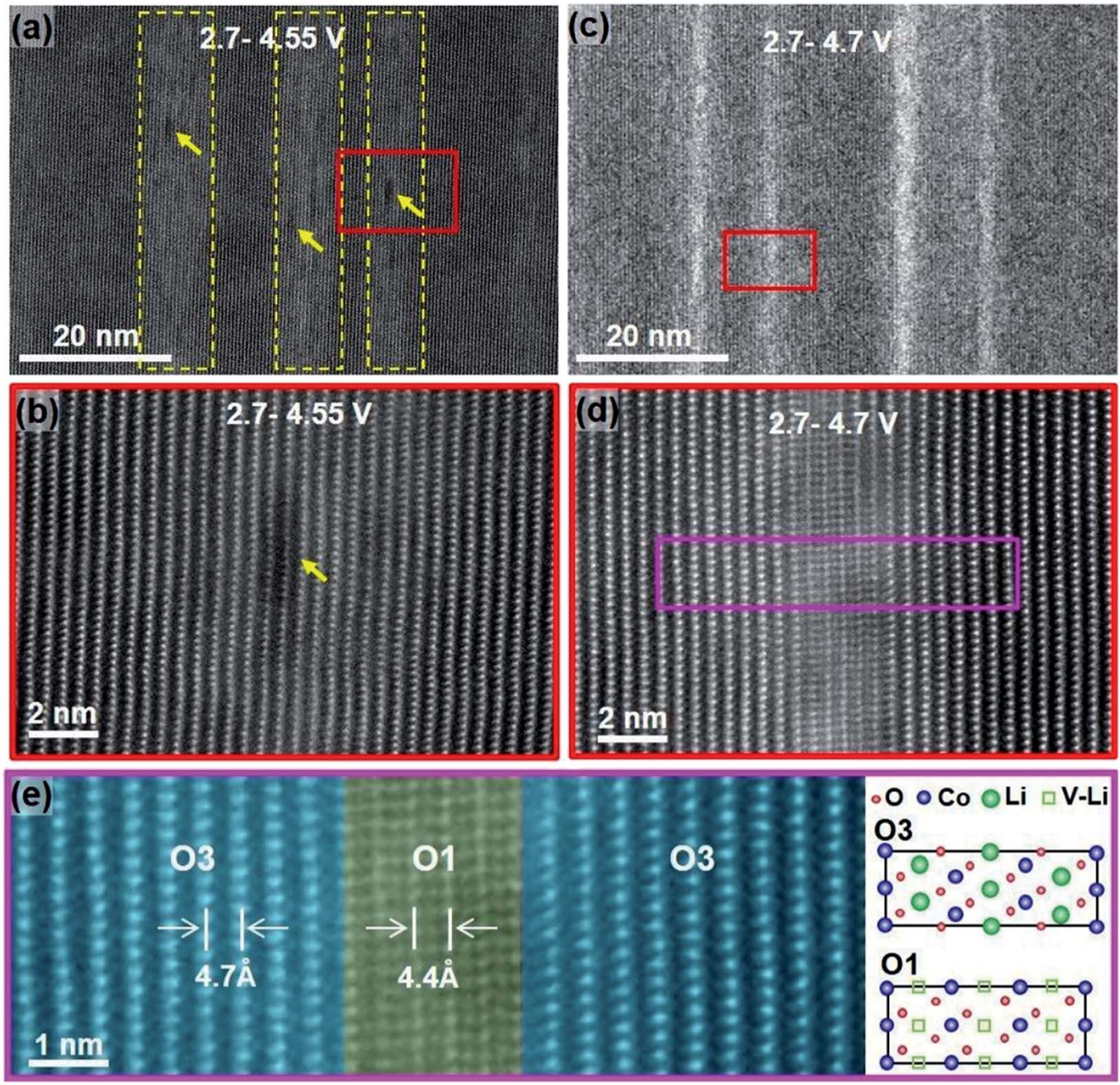

Fig. 4 STEM-HAADF images showing the degradation induced from cycling up to high cutoff voltages for 50 cycles. (a) STEM-HAADF image showing the bright stripes (highlighted by dashed yellow frames) and the dark pits (yellow arrows) on sample cycled between 2.7-4.5 V, (b) Highresolution lattice image to show lattice images in (a), (c) STEM-HAADF image showing the bright stripes formed in the sample cycled between 2.7-4.7 V, (d) lattice image from the region marked in (c), and (e) enlarged lattice image from the pink region in (d). ${ }^{14}$ 

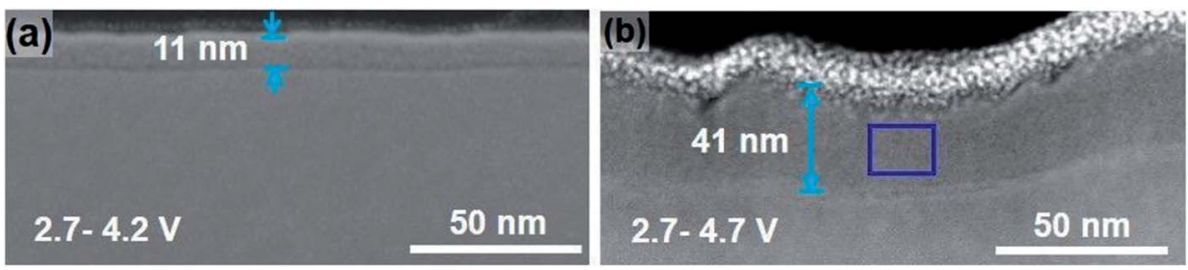

Fig. 5 Effect of high charge cutoff voltage on the thickness of the surface degradation layer. ${ }^{14}$

It was traditionally accepted that the positive charge decrease by $\mathrm{Li}$ ions removal from $\mathrm{Li}_{x} \mathrm{CoO}_{2}$ is compensated by the increased charge of transition metal ions. At the same time, $\mathrm{O}^{2-}$ electronic state is fixed to keep the electro-neutrality of the material. But sensitive techniques to the oxidation state, spin state, bond covalence, and the electronic structures such as EELS and XAS suggest that both oxygen and transition metal ions experience an electronic change, and both participate to the electrochemical reaction. The oxygen K-edge XAS for $\mathrm{Li}_{x^{-}}$ $\mathrm{CoO}_{2}$ shows significant change with respect to Li-ion content compared to the Co $\mathrm{L}_{\mathrm{II}, \mathrm{III}}$-edge XAS, suggesting that the electronic structure of the oxygen ions is more influenced than Co ions by the $\mathrm{Li}^{+}$removal. In addition, the capacity fading upon cycling is explained with the change in the Co-O covalence that changes with the $\mathrm{Li}$ content as a result of the local structural distortion of $\mathrm{CoO}_{6}$ octahedra that accompanies oxygen and cobalt orbitals re-hybridization. ${ }^{13}$

Degradation has a significant contribution to the performance decay of $\mathrm{LiCoO}_{2}$. Bulk structure degradation of $\mathrm{LiCoO}_{2}$ is the main reason for capacity loss at high voltage. Jiang et al. observed that by increasing the cutoff potential from 4.2 to $4.7 \mathrm{~V}$, Li concentration was significantly decreased in the bulk. ${ }^{14}$ Besides, the samples with low Li content suffered from thermal instability when cycled to $4.7 \mathrm{~V}$. The STEM-HAADF images, Fig. 4 , show bright strips, where in the middle, the $\mathrm{O} 1$ phase is identified, and the density of these bright strips increases with increasing the cutoff voltage and the number of cycles. This reveals that there are uneven lithiation and de-lithiation behaviors in the bulk material. Besides structure degradation, interfacial degradation is one of the mechanisms assigned to the failure of layered cathode materials. It originates from the surface phase transformation layer and the cathode electrolyte interface (CEI) layer. The surface degradation is enhanced by increasing the cutoff potential. Fig. 5 shows that the thickness of the degradation layer after 50 cycles is about four times higher in the samples cycled to a cutoff voltage of $4.7 \mathrm{~V}$ compared to that cycled to $4.2 \mathrm{~V}$.

Tremendous efforts have been devoted to improving the functional performance of $\mathrm{Li}_{1-x} \mathrm{CoO}_{2}$ at high voltage and elevated temperatures. Surface coating, doping with foreign

Table 2 The performance of coated $\mathrm{LiCoO}_{2}$ by different materials and different techniques

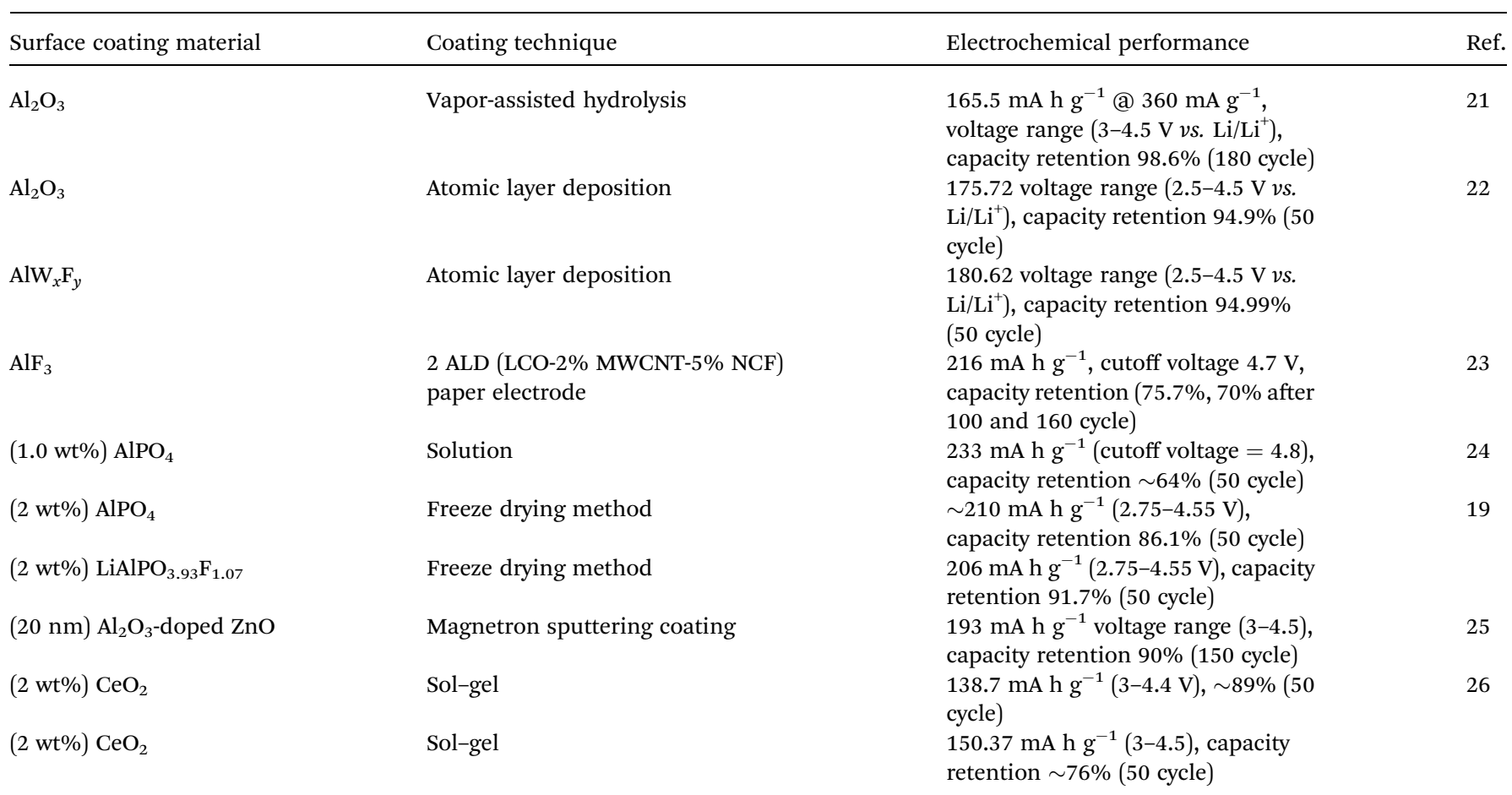




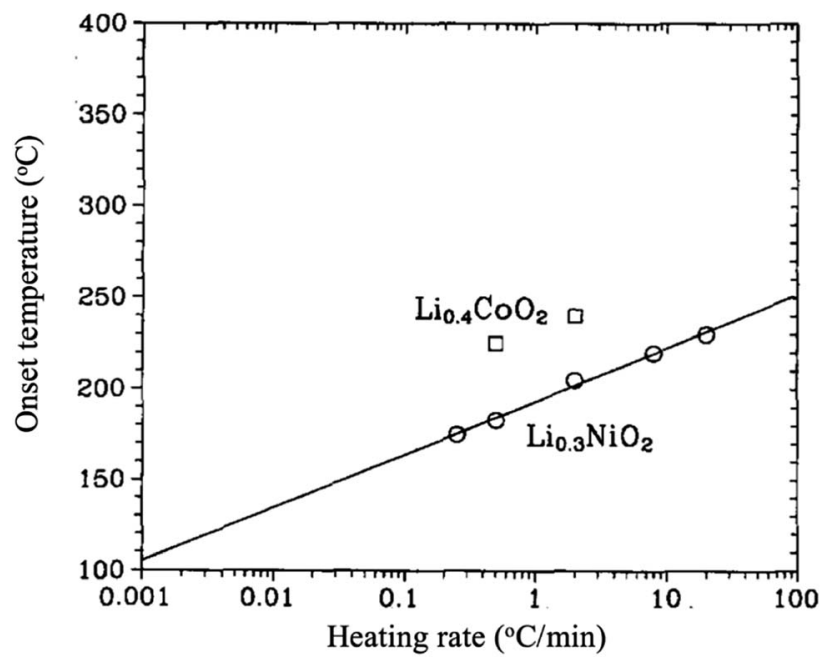

Fig. 6 The onset temperature for oxygen release for $\mathrm{Li}_{0.3} \mathrm{NiO}_{2}$ and $\mathrm{Li}_{0.4} \mathrm{CoO}_{2}$ as a function of heating rate. ${ }^{35}$

elements, and synthesis by wet chemistry methods such as solgel are traditional strategies that have been explored to improve the materials' properties. There are several methods for surface coating, including wet chemistry (sol-gel), chemical polymerization routes, and deposition techniques (sputtering, pulsed laser deposition, atomic layer deposition, chemical vapor deposition)..$^{15}$ The properties of the coated material depend on the homogeneity and thickness of the coating layer. Insulator metals oxides, such as $\mathrm{AlO}_{2}, \mathrm{ZrO}_{2}$, and $\mathrm{AlPO}_{4}$, show outstanding improved performance in terms of capacity retention and rate capability at high voltage compared to the bare $\mathrm{LiCoO}_{2}$. The enhanced electrochemical performance is attributed to (1) the suppression of cobalt dissolution in the electrolyte, (2) the prevention of the direct contact between the cathode and the liquid electrolyte by the inactive coating layer, ${ }^{16}$ and (3) cation diffusion to form $\mathrm{Li}-\mathrm{M}-\mathrm{O}(\mathrm{M}=\mathrm{Al}, \mathrm{Co})$ on the surface during calcination that can suppress the phase transitions and hence decrease the capacity fading especially at high potentials. ${ }^{17}$ Recently, Yano et al. ${ }^{18}$ synthesized $0.5 \mathrm{wt} \% \mathrm{AlO}_{2}$-coated $\mathrm{LiCoO}_{2}$ by the sol-gel method. It shows electrochemical activity at potential $>4.2 \mathrm{~V} v s$. $\mathrm{Li}^{-\mathrm{Li}^{+}}$and an initial capacity of $247 \mathrm{~mA} \mathrm{~h} \mathrm{~g}^{-1}$ at the first cycle and preserved $\sim 82.6 \%$ of its initial capacity after 20 cycles. The improved performance is attributed to the formation of a solid solution surface phase of $\mathrm{LiAlO}_{2}$ and $\mathrm{LiCoO}_{2}$ by the diffusion during the calcination after the sol-gel coating. The coated $\mathrm{LiCoO}_{2}$ shows very small phase transition upon cycling as $\mathrm{Al}^{3+}$ is electrochemically inactive and shares the octahedral sites with $\mathrm{Co}$ ions in the $\mathrm{MO}_{6}$, resulting in a difficultly for both $\mathrm{Li}$ and $\mathrm{O}$ ions to leave the $\mathrm{LiAlO}_{2}$ framework and thereby preserving the surface structure. Table 2 lists several examples of the improved electrochemical performance at high cutoff voltage by coating. Moreover, conductive oxides or Li ion conductors that show low interfacial resistance and maintain high ionic conductivity such as $\mathrm{Al}-\mathrm{ZnO}$, lithium phosphorus oxynitride and lithium tungsten oxide (LWO) are excellent alternatives to the insulator metal oxide coating. ${ }^{19,20}$

\section{2 $\mathrm{LiNiO}_{2}$}

$\mathrm{LiNiO}_{2}$ is considerably less expensive, shows an outstanding attainable capacity of $240 \mathrm{~mA} \mathrm{~h} \mathrm{~g}{ }^{-1},{ }^{27}$ and with less toxicity than $\mathrm{LiCoO}_{2}$. However, it is relatively difficult to synthesize stoichiometric $\mathrm{LiNiO}_{2}$ because of the preferable cation mixing between $\mathrm{Li}$ and $\mathrm{Ni}$ ions to form $\mathrm{Li}_{1 z} \mathrm{Ni}_{1+z} \mathrm{O}_{2} \cdot{ }^{28,29}$ The excess of $\mathrm{Ni}$ ions sitting in the lithium layers hinders the smooth motion of $\mathrm{Li}$ ions during cycling, resulting in poor performance. Moreover, the material goes through several structural transformations upon cycling. For the range $1 \geq x \geq 0.25, \mathrm{Li}_{x} \mathrm{NiO}_{2}$ shows three single-phases; a rhombohedral phase (H1) when 1 $>x>0.75$, a monoclinic phase when $0.75 \geq x \geq 0.45$, a rhombohedral phase $(\mathrm{H} 2)$ when $0.45>x>0.25$, then a two-phase region $(\mathrm{H} 2+\mathrm{H} 3){ }^{30,31}$ In addition, $\mathrm{Li}_{x} \mathrm{NiO}_{2}$ is known for its high thermal instability as it decomposes and liberates oxygen at low temperatures compared to $\mathrm{Li}_{x} \mathrm{CoO}_{2}$ as shown in Fig. 6 . The $\mathrm{O}_{2}$ evolution was found to be dependent on the degree of de-lithiation $(x)$. Lee et al. ${ }^{32}$ synthesized and studied $\left[\mathrm{Li}_{0.948^{-}}\right.$ $\left.\mathrm{Ni}_{0.052}\right]_{3 \mathrm{a}}\left[\mathrm{Li}_{0.003} \mathrm{Ni}_{0.997}\right]_{3 \mathrm{~b}} \mathrm{O}_{2}$. When $x \geq 0.5$, the material decomposes into layered $\mathrm{LiNiO}_{2}$ and spinel $\mathrm{LiNi}_{2} \mathrm{O}_{4}(\mathrm{Fd} 3 \mathrm{~m})$ in the range between 180 and $250{ }^{\circ} \mathrm{C}$. In the composition range 0.5 $>x \geq 0.2$, the material is completely transformed into spinel. Further increasing the temperature, the material turns into rock salt structure $(\mathrm{Fm} 3 \mathrm{~m})$, with all transformations accompanied by oxygen evolution. It has been suggested that the exothermic reaction mechanism is driven by the phase transformations and oxygen evolution, which are originally due to the random mixing between Li and Ni ions. ${ }^{33,34}$ Recently, Yoon et al. ${ }^{27}$ successfully suppressed the $\mathrm{H} 1$ to $\mathrm{H} 2$ phase transition by preparing

Table $3 \quad \mathrm{LiNiO}_{2}$ improved performance by coating $\mathrm{Co}$ and $(\mathrm{Mn}, \mathrm{Co})$ coating found to form a solid solution

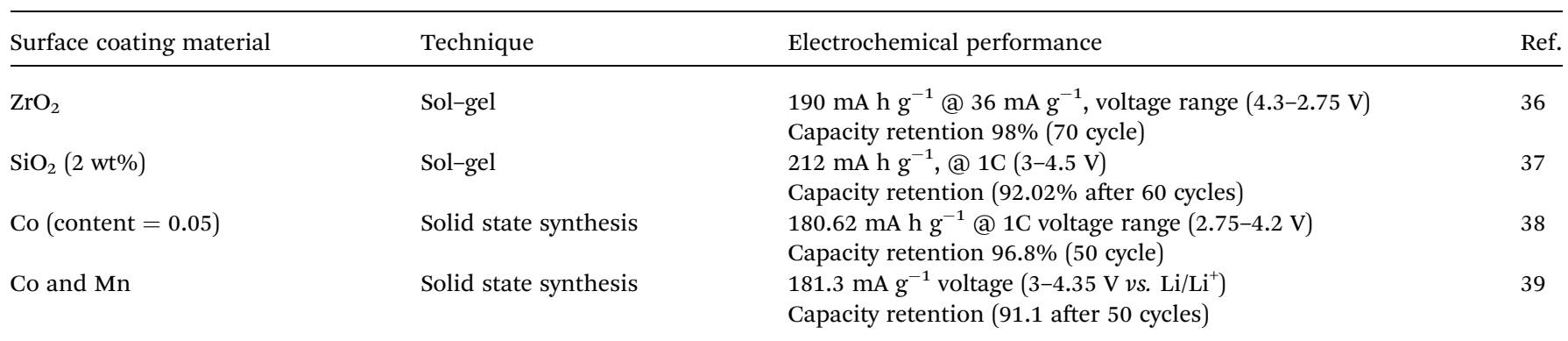


a compact geometry of $\mathrm{LiNiO}_{2}$ in which particles of $200 \mathrm{~nm}$ are packed tightly in a spherical particle of 10 microns. Such geometry minimized the contact between the electrolyte and the surface of the electrode resulting in better structure stability and capacity of 179 at $0.1{ }^{\circ} \mathrm{C}$ rate, $95 \%$ of the capacity was retained after 100 cycles when the cutoff voltage was $4.1 \mathrm{~V}$. Similar to $\mathrm{LiCoO}_{2}$, better thermal, structural, and electrochemical stability is obtained by surface coating with $\mathrm{ZrO}_{2}$ or $\mathrm{SiO}_{2}$, Co and (Mn, Co) as shown in Table 3.

\section{3 $\operatorname{LiCo}_{1-x} \mathrm{Ni}_{x} \mathrm{O}_{2}$}

$\mathrm{LiCo}_{1-x} \mathrm{Ni}_{x} \mathrm{O}_{2}$ was suggested as an alternative to $\mathrm{LiNiO}_{2}$ to merge the relatively better stability of $\mathrm{LiCoO}_{2}$ and the high capacity of $\mathrm{LiNiO}_{2}$. The $\mathrm{LiCo}_{1-x} \mathrm{Ni}_{x} \mathrm{O}_{2}$ solid solution can be formed in the whole $x$ range. The lattice parameters and cell volume increase linearly while $c / a$ decreases obeying Vegard's law when $\mathrm{Ni}$ ions are partially substituted for Co ions. ${ }^{\mathbf{4 0}}$ The higher the Co ions content in $\mathrm{LiCo}_{1-x} \mathrm{Ni}_{x} \mathrm{O}_{2}$, the more stable the structure is. Co substitution suppresses the non-stoichiometry of $\mathrm{Li}_{1-z} \mathrm{Ni}_{1+z} \mathrm{O}_{2}$ from $z=0.04$ to 0.01 when $\mathrm{Co}$ is increased from 0 to 0.2 , and a pure stoichiometric $2 \mathrm{D}$ structure of $\mathrm{LiCo}_{1-x} \mathrm{Ni}_{x} \mathrm{O}_{2}$ was observed when Co content reached $0.3 .^{41}$ The best performance of $\mathrm{LiCo}_{1-x} \mathrm{Ni}_{x} \mathrm{O}_{2}$ was obtained for $0.1 \geq x \geq$ 0.3. ${ }^{42}$ Differential scanning calorimetry for $\mathrm{LiCo}_{1-x} \mathrm{Ni}_{x} \mathrm{O}_{2}$ proved relatively higher safety and thermal stability than $\mathrm{LiNiO}_{2}$ at $x=$
$0.1 \geq x \geq 0.3$ at cutoff voltages of 4.2 and $4.3 \mathrm{~V} v s$. $\mathrm{Li} / \mathrm{Li}^{+} \cdot{ }^{43} \mathrm{Upon}$ increasing the Co content, the exothermic reaction shifts toward higher temperatures, and its enthalpy decreases. In addition, when the cell is charged to higher potential, the exothermic event takes place at a lower temperature in agreement with the fact that the lower the $\mathrm{Li}^{+}$content, the lower the thermal stability of these oxide materials is. Recently, Xie et al. ${ }^{\mathbf{4 4}}$ doped $\mathrm{Li}(\mathrm{Co}, \mathrm{Ni}) \mathrm{O}_{2}$ with $\mathrm{Mg}$ ions to obtain highly structural, thermal, and electrochemical stable structure. Note that $80.1 \%$ of its initial capacity $\left(214 \mathrm{~mA} \mathrm{~h} \mathrm{~g}^{-1}\right.$ ) was maintained after 500 cycles compared to $56.3 \%$ without $\mathrm{Mg}$ ions. $\mathrm{The}_{\mathrm{Mg}^{2+}}$ prevented the $\mathrm{Li}^{+} / \mathrm{Ni}^{2+}$ site mixing, suppressed the migration of $\mathrm{Ni}$ ions to the Li layers, and showed a pillar effect in the position of the $\mathrm{Li}$ ions, which improved the thermal stability significantly even at such a high voltage as $4.7 \mathrm{~V} v s . \mathrm{Li}^{+} / \mathrm{Li}^{45}$ Table 4 summarizes the thermal behavior of different transition metal oxides.

\section{4 $\mathrm{LiMnO}_{2}$}

Manganese oxides are promising cathode materials due to their less toxicity and lower cost than cobalt and nickel oxides. Ion exchange is a successful method to synthesize layered $\mathrm{LiMnO}_{2}$ by exchanging $\mathrm{Na}$ in $\mathrm{NaMnO}_{2}$ with $\mathrm{Li}^{.}{ }^{50}$ Truly layered $\mathrm{LiMnO}_{2}$ with $\alpha-\mathrm{NaFeO}_{2}$ like structure is thermodynamically unstable because of the Jahn-Teller effect that distorts the structure to less symmetry orthorhombic $\left(o-\mathrm{LiMnO}_{2}\right)$ with the space group

Table 4 Thermal behavior of different transition metal oxides

\begin{tabular}{|c|c|c|c|c|}
\hline Composition & $\begin{array}{l}\text { Decomposition } \\
\text { temperature }\left({ }^{\circ} \mathrm{C}\right)\end{array}$ & $\begin{array}{l}\text { Cutoff voltage } \\
\text { (V) }\end{array}$ & Heat generated $\left(\mathrm{J} \mathrm{g}^{-1}\right)$ & Ref. \\
\hline $\mathrm{LiNiO}_{2}$ & 181.2 & 4.3 & 1965 & 46 \\
\hline $\mathrm{LiNi}_{0.9} \mathrm{Co}_{0.07} \mathrm{Mg}_{0.03} \mathrm{O}_{2}$ & 243.7 & 4.3 & 543.2 & 45 \\
\hline $\mathrm{LiNi}_{0.9} \mathrm{Co}_{0.07} \mathrm{Mg}_{0.03} \mathrm{O}_{2}$ & 237.2 & 4.5 & 596.8 & 45 \\
\hline $\mathrm{LiNi}_{0.9} \mathrm{Co}_{0.07} \mathrm{Mg}_{0.03} \mathrm{O}_{2}$ & 211.6 & 4.7 & 667.5 & 45 \\
\hline $\mathrm{LiNi}_{0.80} \mathrm{Co}_{0.19} \mathrm{Mg}_{0.01} \mathrm{O}_{2}$ & 219.6 & 4.3 & 845.7 & 48 \\
\hline $\mathrm{LiNi}_{0.78} \mathrm{Co}_{0 \cdot 19} \mathrm{Mg}_{0.01} \mathrm{Al}_{0.02} \mathrm{O}_{2}$ & 221.9 & 4.3 & 394.6 & 48 \\
\hline $\mathrm{Li}\left[\mathrm{Ni}_{0.6} \mathrm{Co}_{0.2} \mathrm{Mn}_{0.2}\right] \mathrm{O}_{2}$ & 201 & 4.3 & 1670 & 49 \\
\hline $\mathrm{Li}\left[\mathrm{Ni}_{0.9} \mathrm{Co}_{0.05} \mathrm{Mn}_{0.05}\right] \mathrm{O}_{2}$ & 272 & 4.3 & 769 & 49 \\
\hline $\mathrm{Li}\left[\mathrm{Ni}_{1 / 3} \mathrm{Co}_{1 / 3} \mathrm{Mn}_{1 / 3}\right] \mathrm{O}_{2}$ & 261.5 & 4.5 & 1998 & 47 \\
\hline
\end{tabular}

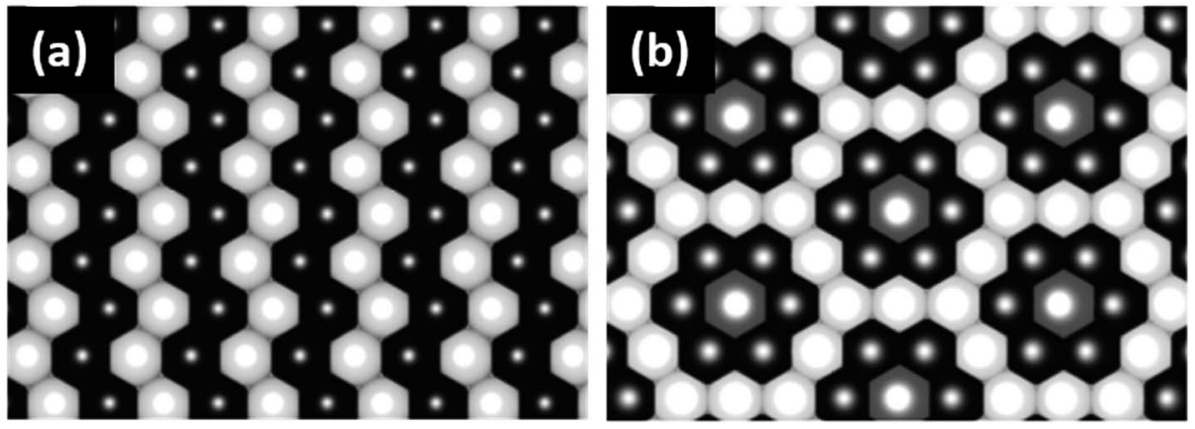

Fig. 7 (a) TM layer ordering of the flower structure and (b) transition metal layer ordering of the zigzag structure. ${ }^{59}$ 

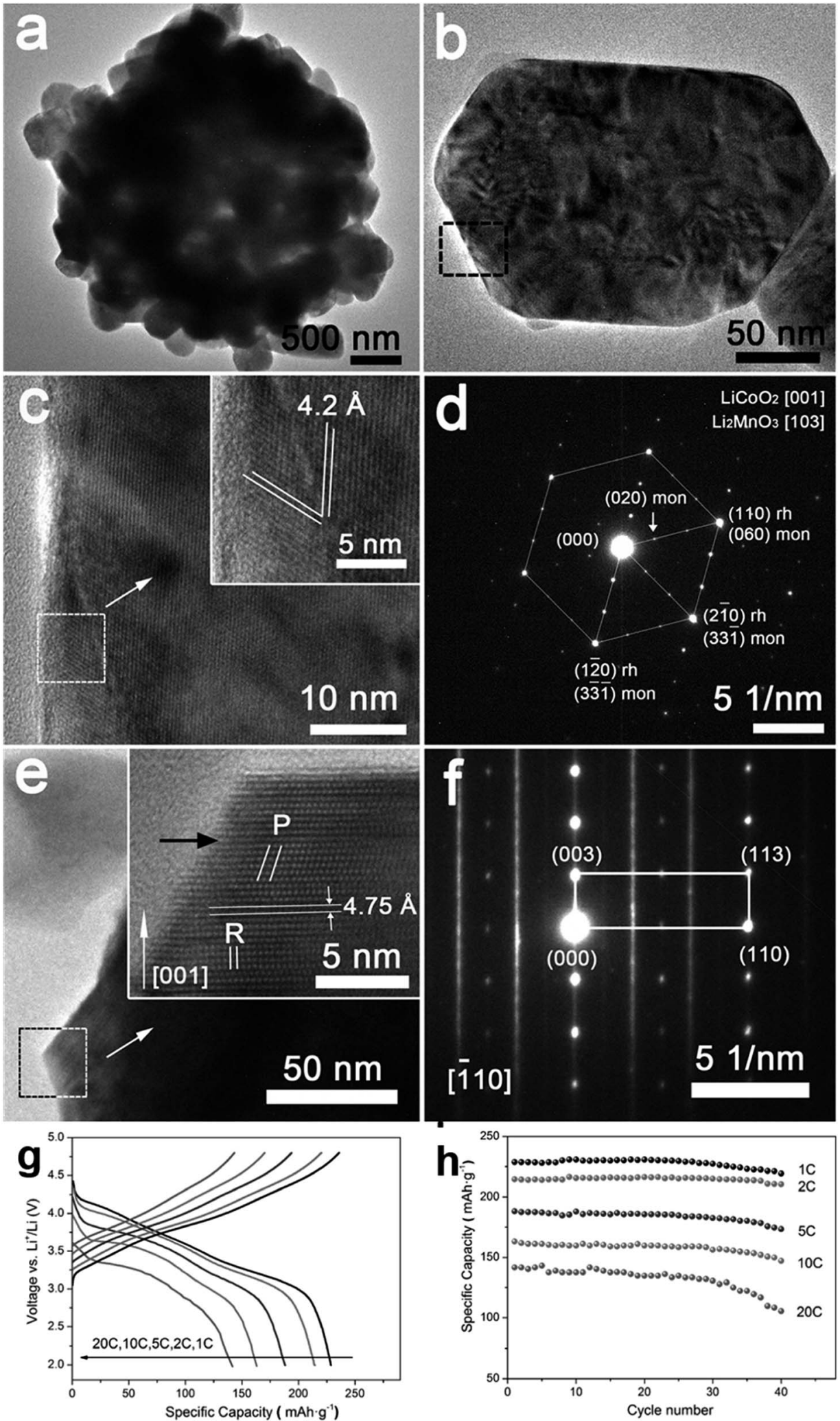

Fig. 8 (a-f) Hierarchical $\mathrm{Li}_{1.2} \mathrm{Ni}_{0.2} \mathrm{Mn}_{0.6} \mathrm{O}_{2}$ nanoplates with exposed $\{010\}$ planes as high-performance cathode material for lithium-ion batteries, (g) discharge curves of half cells based on the $\mathrm{Li}_{1.2} \mathrm{Ni}_{0.2} \mathrm{Mn}_{0.6} \mathrm{O}_{2}$ hierarchical structure nanoplates at $1 \mathrm{C}, 2 \mathrm{C}, 5 \mathrm{C}, 10 \mathrm{C}$, and $20 \mathrm{C}$ rates after charging at $\mathrm{C} / 10$ rate to $4.8 \mathrm{~V}$, and (h) the rate capability at $1 \mathrm{C}, 2 \mathrm{C}, 5 \mathrm{C}, 10 \mathrm{C}$, and $20 \mathrm{C}$ rates. ${ }^{88}$ 
Pmmn or monoclinic $\left(m-\mathrm{LiMnO}_{2}\right)$ with the space group $\mathrm{C2} / \mathrm{m}^{\mathbf{5 1}}$ Monoclinic $\mathrm{LiMnO}_{2}$ is thermodynamically less stable than the spinel and orthorhombic lithium manganese oxides because of the antiferromagnetic interactions between $\mathrm{Mn}^{3+}$ distorting the $\mathrm{MnO}_{6}$ octahedra. ${ }^{52}$ This results in a transition from the initial monoclinic to hexagonal at the first charge then to spinel gradually upon cycling. ${ }^{53}$ This transformation takes place through the migration of $25 \%$ of $\mathrm{Mn}$ ions from the octahedral sites in the transition metal layer to the lithium layer, and the $\mathrm{Li}$ ions move to tetrahedral sites. Stabilization of the layered structure can be obtained by partially substituting Mn ions by antiferromagnetic elements such as $\mathrm{Al}$ or $\mathrm{Cr}^{.54,55}$ Many studies have been carried out on the structural and electrochemical properties of the $\mathrm{Li}-\mathrm{Ni}-\mathrm{Mn}-\mathrm{O}$ and $\mathrm{Li}-\mathrm{Ni}-\mathrm{Mn}-\mathrm{Co}-\mathrm{O}$ systems as alternatives to the single oxides.

\section{5 $\mathrm{LiNi}_{0.5} \mathrm{Mn}_{0.5} \mathrm{O}_{2}$}

$\mathrm{LiNi}_{0.5} \mathrm{Mn}_{0.5} \mathrm{O}_{2}$ is a $4 \mathrm{~V}$ cathode material with a theoretical capacity of $280 \mathrm{~mA} \mathrm{~h} \mathrm{~g}{ }^{-1}$. During charging, $\mathrm{Ni}^{2+}$ is oxidized to $\mathrm{Ni}^{4+}$ through two stages, while $\mathrm{Mn}^{4+}$ is electrochemically inactive and remains unchanged. ${ }^{56,57}$ The presence of the stable $\mathrm{Mn}^{4+}$ octahedral ions stabilizes the $\mathrm{LiNi}_{0.5} \mathrm{Mn}_{0.5} \mathrm{O}_{2}$ structure during $\mathrm{Li}^{+}$removal, thus avoiding the Jahn-Teller distortion that is associated with the presence of $\mathrm{Mn}^{3+}$. There are different structural models that explain the composition of the transition metal layer in $\mathrm{LiNi}_{0.5} \mathrm{Mn}_{0.5} \mathrm{O}_{2}$; the most stable and lowest energy structures are shown in Fig. 7. The zigzag ordering of $\mathrm{Ni}^{2+}$ and $\mathrm{Mn}^{4+}$ is preferred if there is no $\mathrm{Li}^{+} / \mathrm{Ni}^{2+}$ mixing, while the flower order is preferred if there is $\mathrm{Li}^{+} / \mathrm{Ni}^{2+}$ mixing. The flower structure is ordered in such a way that the $\mathrm{Li}^{+}$is located in the center of an $\mathrm{Mn}^{4+}$ hexagon surrounded by $\mathrm{Ni}^{2+}{ }^{28,59} \mathrm{LiNi}_{0.5} \mathrm{Mn}_{0.5} \mathrm{O}_{2}$ is indexed in the $R \overline{3} m$ space group, with around 8 to $10 \%$ anti-cite mixing between $\mathrm{Li}$ and $\mathrm{Ni}$ usually takes place. ${ }^{60} \mathrm{Li}^{+}$prefers to occupy positions close to $\mathrm{Mn}^{4+}$ ions than $\mathrm{Ni}^{2+}$ in the transition metal layer. ${ }^{58}$ Therefore, $\mathrm{Li}, \mathrm{Ni}$, and $\mathrm{Mn}$ ions are not randomly distributed in the transition metal layer. Single crystal selected area electron diffraction patterns of pristine $\mathrm{LiNi}_{0.5} \mathrm{Mn}_{0.5} \mathrm{O}_{2}$ reveal the presence of superlattice reflections indicating the long-range ordering of Li-rich and Li-deficient sites in the transition metal layer. The superlattice reflections are indexed in $\sqrt{3 \mathrm{a}_{\mathrm{Hex}}} \times \sqrt{3 \mathrm{a}_{\mathrm{Hex}}} \times \mathrm{c}_{\mathrm{Hex}}$. and correspond to a trigonal structure with the space group $P 3_{1} 12 .{ }^{61,62}$ Investigation of the local structure upon charging suggested the disappearance of $\mathrm{Li}^{+}$located in the transition metal layer very early during the first charge. ${ }^{63} \mathrm{Li}^{+}$migrates to the tetrahedral sites that share faces with vacant octahedral sites in the transition metal layer. The presence of $\mathrm{Li}$ in the tetrahedral sites reflects negatively on the electrochemical performance of the material. Because $\mathrm{Li}_{\text {tet }}{ }^{+}$ is very energetically stable and requires high potential to be removed, which decreased the capacity obtained in the practical voltage range. ${ }^{64}$ Regarding the $\mathrm{Ni}$ ions in the $\mathrm{Li}$ layer, by charging above $4.6 \mathrm{~V}, 75 \%$ of $\mathrm{Ni}_{\mathrm{Li}}$ ions migrate to vacant $\mathrm{Li}$ positions in the transition metal (TM) layer. ${ }^{65}$ The migration of $\mathrm{Ni}$ ions to the TM layer is partly a reversible process and reflects on the weaken or disappearance of the $\sqrt{3 \mathrm{a}_{\mathrm{Hex}}} \times \sqrt{3 \mathrm{a}_{\mathrm{Hex}}} \times \mathrm{c}_{\mathrm{Hex}}$. c supercell. Simply, in other words, the $\mathrm{Ni}^{2+} / \mathrm{Li}^{+}$mixing was decreased by cycling compared to pristine $\mathrm{LiNi}_{0.5} \mathrm{Mn}_{0.5} \mathrm{O}_{2}$.

\section{6 $\operatorname{LiNi}_{x} \mathrm{Co}_{y} \mathrm{Mn}_{1-x-y} \mathrm{O}_{2}$}

The mixed transition metal oxides family $\mathrm{LiNi}_{x} \mathrm{Co}_{1-2 x} \mathrm{Mn}_{x} \mathrm{O}_{2}$ (ref. 66) was proposed to avoid the shortcoming of each individual oxide such as low stability, safety, and specific capacity. The cation mixing in this compound is lower than at $\mathrm{LiNi}_{0.5} \mathrm{Mn}_{0.5} \mathrm{O}_{2}$, and it increases by increasing the $\mathrm{Ni}$ content. $\mathrm{LiNi}_{1 / 3} \mathrm{Co}_{1 / 3} \mathrm{Mn}_{1 / 3} \mathrm{O}_{2}$ was found to be promising among the series of materials in the composition range $0 \leq x \leq \frac{1}{2}$. $\mathrm{LiNi}_{1 / 3} \mathrm{Co}_{1 / 3} \mathrm{Mn}_{1 / 3} \mathrm{O}_{2}$ showed a specific capacity of $200 \mathrm{~mA} \mathrm{~h} \mathrm{~g}{ }^{-1}$ when charged up to $4.6 \mathrm{~V} v s$. $\mathrm{Li} / \mathrm{Li}^{+}$. It crystallizes in the typical layered structure of $\alpha-\mathrm{NaFeO}_{2}$ with $R \overline{3} m$ space group with the electronic charge of $\mathrm{Co}, \mathrm{Ni}$, and Mn being $+3,+2$, and +4 , respectively. Several authors debated its electronic structure upon the de-intercalation of lithium. Tsai et al. and Yoon et al. reported that its electrochemical performance is attributed to the redox reactions $\mathrm{Ni}^{2+} / \mathrm{Ni}^{3+}$ at the surface and $\mathrm{Ni}^{3+} / \mathrm{Ni}^{4+}$ in bulk, while the oxidation states of $\mathrm{Mn}^{4+}$ and $\mathrm{Co}^{3+}$ remain unchanged. ${ }^{67,68}$ In addition, K-edge XAS of the oxygen ions shows that it plays an essential role in the charge compensation in its site during $\mathrm{Li}^{+}$de-intercalation. On the other hand, Kim et $a .^{69}$ reported that the charge compensation during charging is due to the redox $\mathrm{Ni}^{2+} / \mathrm{Ni}^{4+}$ and $\mathrm{Co}^{3+} / \mathrm{Co}^{4+}$ while $\mathrm{Mn}^{4+}$ is stable.

\subsection{Li-rich cathode materials}

4.7.1 $\mathrm{Li}_{2} \mathrm{MnO}_{3} \cdot \mathrm{Li}_{2} \mathrm{MnO}_{3}$ is one of the $x \mathrm{Li}_{2} \mathrm{MnO}_{3} \cdot(1-x)$ $\mathrm{LiMO}_{2}$ family of materials when $x=0$. It possesses layered structure $\mathrm{Li}_{3 \mathrm{a}}\left[\mathrm{Li}_{1 / 3} \mathrm{Mn}_{2 / 3}\right]_{3 \mathrm{~b}} \mathrm{O}_{2}$ with $C 2 / m$ space group. In $\mathrm{Li}_{2} \mathrm{MnO}_{3}$, the $\mathrm{Mn}^{4+}$ is electrochemically inactive because it cannot be oxidized to a higher oxidation state. Surprisingly, $\mathrm{Li}^{+}$ could be inserted and extracted from $\mathrm{Li}_{2} \mathrm{MnO}_{3}$ when activated at 4.5 $\mathrm{V}^{70-72}$ This material has promoted many debates on the mechanism of the electrochemical behavior and $\mathrm{Li}^{+}$extraction. During the first charge, the $\mathrm{Li}^{+}$extraction was found to be accompanied by oxygen evolution, leading to the removal of $\mathrm{Li}_{2} \mathrm{O}$, resulting in electrochemical activation of $\mathrm{Li}_{2} \mathrm{MnO}_{3} .^{73}$ Robertson et al. suggested that there is a proton exchange with $\mathrm{Li}^{+}$to form $\mathrm{Li}_{2-x} \mathrm{H}_{x} \mathrm{MnO}_{3},{ }^{74}$ which can take place after the production of hydrogen by electrolyte oxidation. The presence of $\mathrm{H}$ in the oxide layers forming $\mathrm{O}-\mathrm{H}-\mathrm{O}$ bond leads to a change to a more stable stacking sequence from $\mathrm{O} 3(\mathrm{ABCABC})$ to P3(ABBCCA). Another proposed mechanism based on DFT calculations shows that the electrochemical behavior is attributed to the charge compensation by the oxidation of anion "oxygen". ${ }^{75}$ However, the thermodynamically unstable localized holes at the beginning of the oxidation result in the evolution of oxygen. This study showed that the structural transformation to spinel is driven by the oxygen dimerization, which facilitates the Mn ions migration onto octahedral sites in the vacated lithium layers. Rana et al. suggested that both oxygen oxidation and proton exchange are responsible for the electrochemical behavior of $\mathrm{Li}_{2} \mathrm{MnO}_{3}{ }^{76}$ Oxygen and $\mathrm{Li}^{+}$are removed from the material, leaving layered $\mathrm{Mn}_{2} \mathrm{O}$ and the structure change from $\mathrm{O} 3$ to $\mathrm{P} 3$ due to the proton- $\mathrm{Li}^{+}$exchange. This structural change 
is reversible, and it turns to $\mathrm{O} 3$ during the following discharge, but there is an irreversible oxygen loss due to the material activation during the first cycle. The repeated $\mathrm{Li}^{+}-\mathrm{H}^{+}$exchange, which leads to the change from $\mathrm{O} 3$ to P3 and the reverse upon cycling, was found to be responsible for the poor electrochemical performance of $\mathrm{Li}_{2} \mathrm{MnO}_{3}$. The repeated shearing of oxygen layers results in permeant damage of the structure upon cycling.

4.7.2 $x \mathrm{Li}_{2} \mathrm{MnO}_{3} \cdot(1-x) \mathrm{LiMO}_{2} \cdot x \mathrm{Li}_{2} \mathrm{MnO}_{3} \cdot(1-x) \mathrm{LiMO}_{2}(\mathrm{M}$ $=\mathrm{Ni}, \mathrm{Co}, \mathrm{Cr}$ ) are attractive materials due to their high-energy density and low cost. $\mathrm{Li}\left[\mathrm{Li}_{1 / 3-2 x / 3} \mathrm{Ni}_{x} \mathrm{Mn}_{2 / 3-x / 3}\right] \mathrm{O}_{2}$ is a layered oxide composed of two phases: monoclinic $x \mathrm{Li}_{2} \mathrm{MnO}_{3}$ and hexagonal $(1-x) \mathrm{LiMO}_{2}$ integrated into a single nanoparticle. ${ }^{77,78}$ In the range $0 \leq x \leq 1 / 3$, the $\mathrm{Li}$ and transition metals are ordered in the transition metal layer on a $\sqrt{3 \mathrm{a}_{\text {Hex. }}} \times \sqrt{3 \mathrm{a}_{\text {Hex. }}}$ super structure. ${ }^{79}$ It exhibits high voltage during charging $(>4.5 \mathrm{~V})$, high specific capacity $\left(>250 \mathrm{~mA} \mathrm{~h} \mathrm{~g}^{-1}\right)$, and high energy density. ${ }^{\mathbf{7 0 , 8 0 , 8 1}}$ The electrochemical behavior of Li-rich, layered oxides is divided into two stages. The first is before $4.4 \mathrm{~V}$ when the $\mathrm{Li}^{+}$is extracted from $\mathrm{LiMO}_{2}$. The second starts at $4.5 \mathrm{~V}$ when the $\mathrm{Li}_{2} \mathrm{O}$ is extracted to activate $\mathrm{Li}_{2} \mathrm{MnO}_{3}$. The Li-rich, layered oxides suffer from some drawbacks such as an irreversible capacity loss due to the irreversible extraction of $\mathrm{Li}_{2} \mathrm{O}$ and the reaction with electrolyte at high potential, poor rate capability due to high charge transfer resistance and a voltage fade upon cycling. The origin of the voltage fade was suggested to be the transition from layered to spinel, which is accompanied by an irreversible transition metals migration to the Li-ions layers. ${ }^{82-85}$ Despite the fact that the nanomaterials with the high surface area are known for their undesired side reactions with the electrolyte, reduction of particle size of Lirich materials to the nanoscale shows a better rate capability and a decrease in the diffusion path of Li ions. ${ }^{\mathbf{8 6 , 8 7}}$ Moreover, decreasing the interface area between the electrode and the electrolyte by controlling the morphology of the nanomaterials could suppress the erosion from the electrolyte and improve the cycling performance. Taking $\mathrm{Li}_{1.2} \mathrm{Ni}_{0.2} \mathrm{Mn}_{0.6} \mathrm{O}_{2}$ as an example, hierarchical nanoplates structure shows outstanding rate capability as shown in Fig. 8, with specific capacity of $\sim 231$, $216.5,188,163$ and $142 \mathrm{~mA} \mathrm{~h} \mathrm{~g}^{-1}$ at as high rates as 1C, 2C, 5C, 10C, and 20C.$^{87}$ Furthermore, it shows high capacity retention of $95.5 \%$ and $86.6 \%$ after 60 cycles for $1 \mathrm{C}$ and $2 \mathrm{C}$ rates, respectively. The classical voltage decay of Li-rich material was still observed due to the transition to spinel. An expected significant decrease in capacity retention to $68 \%$ occurred when the hierarchical structure was damaged by ultrasonic treatment.

\section{Spinel positive electrode materials}

\section{1 $\mathrm{LiMn}_{2} \mathrm{O}_{4}$}

Spinel $\mathrm{LiMn}_{2} \mathrm{O}_{4}$ is one of the most attractive energy storage materials due to its low cost and reversible and fast intercalation and de-intercalation of Li ions. ${ }^{89-91}$ The $\mathrm{LiMn}_{2} \mathrm{O}_{4}$ spinel structure (space-group: $F d 3 m$ ), consists of oxygen ions close-packed array occupy the $32 \mathrm{e}$ position, Mn ions occupy the octahedral site 16d,

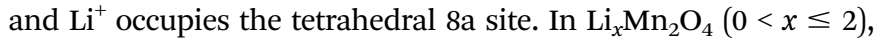
$\mathrm{Mn}_{2} \mathrm{O}_{4}$ provides a 3-dimensional host network for $\mathrm{Li}^{+}$. When the voltage is $\sim 4 \mathrm{~V}, \mathrm{Li}$ ions are hosted in the 8 a site in the range $0<x \leq$ 1. However, at $3 \mathrm{~V}$, the inserted $\mathrm{Li}^{+}$ions occupy the octahedral $16 \mathrm{c}$ sites, which share faces with the 8 a tetrahedral. The Li-ions at the $8 \mathrm{a}$ sites move to the empty $16 \mathrm{c}$ sites, resulting in a first-order phase transition to $\mathrm{Li}_{2} \mathrm{Mn}_{2} \mathrm{O}_{4}$. In addition, when $\mathrm{Mn}^{3+}$ concentration increases, Jahn-Teller distortion occurs to decrease the crystal symmetry from cubic to tetragonal $\mathrm{Li}_{2} \mathrm{Mn}_{2} \mathrm{O}_{4}$. Therefore, it is believed that the electrochemical performance of spinel $\mathrm{LiMn}_{2} \mathrm{O}_{4}$ is better at $4 \mathrm{~V}$ than $3 \mathrm{~V}$. However, it is still possible to observe the presence of $\mathrm{Li}_{2} \mathrm{Mn}_{2} \mathrm{O}_{4}$ on the surface of $\mathrm{LiMn}_{2} \mathrm{O}_{4}$ in a $4 \mathrm{~V}$ cell at the end of the discharge process as an over-discharge product. ${ }^{92}$ Then, $\mathrm{MnO}$ could be dissolved from $\mathrm{Li}_{2} \mathrm{Mn}_{2} \mathrm{O}_{4}$, resulting in the formation of $\mathrm{Li}_{2} \mathrm{MnO}_{3}$ on the surface of $\mathrm{LiMn}_{2} \mathrm{O}_{4} \cdot{ }^{93} \mathrm{MnO}$ dissolution is attributed to the formation of $\mathrm{HF}$ acid from the electrolyte.

$$
\mathrm{Li}_{2} \mathrm{Mn}_{2} \mathrm{O}_{4} \rightarrow \mathrm{Li}_{2} \mathrm{MnO}_{3}+\mathrm{MnO}
$$

Generally, $\mathrm{LiMn}_{2} \mathrm{O}_{4}$ suffers from a capacity fading problem, especially at a temperature of $55^{\circ} \mathrm{C}$ due to the phase transitions discussed earlier as well as the chemical instability of the spinel $\mathrm{LiMn}_{2} \mathrm{O}_{4}$ with the electrolyte, resulting in the dissolution of $\mathrm{Mn}$ ions. ${ }^{94}$ The improvement of the electrode and electrolyte interface region by providing a protective coating on the material surface to decrease the direct contact with the electrolyte is one of the most extensively studied methods to avoid the previously mentioned problems. Electrochemically active materials coatings, such as $\mathrm{LiNi}_{0.5} \mathrm{Mn}_{1.5} \mathrm{O}_{2}, \mathrm{LiCoO}_{2}, \mathrm{Li}_{4} \mathrm{Ti}_{5} \mathrm{O}_{12}$, and metal oxide coating by $\mathrm{B}_{2} \mathrm{O}_{3}, \mathrm{ZnO}$, or $\mathrm{TiO}_{2}$, show improved performance of the material at room temperature and $55{ }^{\circ} \mathrm{C} . .^{95-99}$ Doping with $\mathrm{Al}$, $\mathrm{Co}, \mathrm{Cr}$, or Ni improved the cyclability but at the expense of the

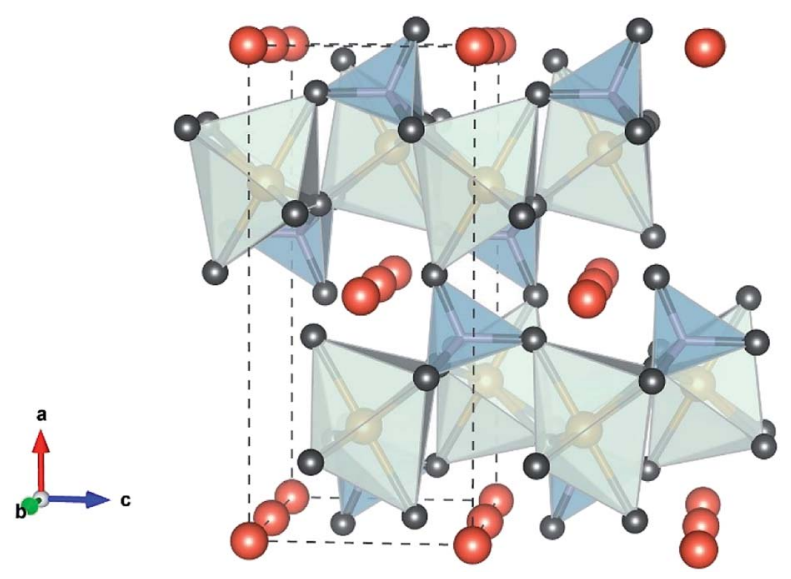

Fig. 9 Polyhedral representation of the olivine structure. $\mathrm{FeO}_{6}$ (light green), $\mathrm{PO}_{4}$ (gray), and the $\mathrm{Li}^{+}$(orange) "by VESTA".

Table 5 Cell parameters of $\mathrm{LiMPO}_{4}(\mathrm{M}=\mathrm{Fe}, \mathrm{Mn}$, Co or Ni)

\begin{tabular}{lllll}
\hline $\mathrm{LiMPO}_{4}$ & $a$ & $b$ & $c$ & Ref. \\
\hline $\mathrm{LiFePO}_{4}$ & $10.3377(5)$ & $6.0112(2)$ & $4.6950(2)$ & 107 \\
$\mathrm{LiMnPO}_{4}$ & $10.4472(5)$ & 6.11049 & $4.7459(2)$ & 108 \\
$\mathrm{LiCoPO}_{4}$ & 10.20 & 5.92 & 4.70 & 109 \\
$\mathrm{LiNiPO}_{4}$ & 10.060 & 5.776 & 4.683 & 110
\end{tabular}


initial capacity. ${ }^{\mathbf{1 0 0 , 1 0 1}}$ Furthermore, the anionic substitution by $\mathrm{F}$, along with the cationic substitution, show improved performance. ${ }^{102,103}$

\section{$5.2 \quad \mathrm{LiNi}_{0.5} \mathrm{Mn}_{1.5} \mathrm{O}_{4}$}

The substitution of $25 \%$ of $\mathrm{Mn}$ for Ni ions in the spinel $\mathrm{LiMn}_{2} \mathrm{O}_{4}$ results in one of the most promising materials for high energy applications ( $\mathrm{LiNi}_{0.5} \mathrm{Mn}_{1.5} \mathrm{O}_{4}$ ) because it shows one dominant voltage plateau at $4.7 \mathrm{~V}$, while another doped $\mathrm{LiMn}_{2} \mathrm{O}_{4}$ show two plateaus between 4 and $5 \mathrm{~V}$. Electrochemical performance of spinel $\mathrm{LiNi}_{0.5} \mathrm{Mn}_{1.5} \mathrm{O}_{2}$ is attributed to the $\mathrm{Ni}^{2+} / \mathrm{Ni}^{4+}$ redox at $4.7 \mathrm{~V}$ with $\mathrm{Mn}^{4+}$ remains unchanged. $\mathrm{LiNi}_{0.5} \mathrm{Mn}_{1.5} \mathrm{O}_{2}$ orders in two different space groups $\mathrm{Fd} 3 \mathrm{~m}$ or $\mathrm{P}_{3} 32$. The spinel type that exhibits $F d 3 m$ space group is a disordered phase that has a face centered cubic structure in which Li ions occupy the 8a sites, the transition metals $\mathrm{Ni}$ and $\mathrm{Mn}$ ions randomly occupy the $16 \mathrm{~d}$ sites, and the ccp oxygen array occupies the 32e sites. The spinel type that exhibits $P 4_{3} 32$ space group is an ordered phase that has a primitive cubic structure in which the Li ions occupy the $8 \mathrm{c}$ positions, $\mathrm{Mn}$ and $\mathrm{Ni}$ are regularly ordered in the $12 \mathrm{~d}$ and $4 \mathrm{a}$ sites, respectively, while the oxygen ions occupy both the $24 \mathrm{e}$ and $8 \mathrm{c}$ positions. ${ }^{104}$ The disordered structure exhibits better performance than the ordered spinel structure. ${ }^{\mathbf{1 0 5}}$ Despite its voltage is considered as one of the highest among other available materials, this voltage is outside the stability window of the electrolyte, which leads to the formation of SEI that affects the kinetics of the electrochemical insertion and de-insertion of $\mathrm{Li}$ ions. The stability of the SEI can be improved by surface modification via coating. ${ }^{106}$ In addition, coating plays a beneficial role in suppressing the dissolution of $\mathrm{Mn}$ ions from $\mathrm{Li} \mathrm{Ni} \mathrm{N}_{0.5} \mathrm{Mn}_{1.5} \mathrm{O}_{4}$.

\section{Polyanionic positive electrode materials}

\subsection{Phosphates-based cathode materials}

Polyanionic olivine $\mathrm{LiMPO}_{4}(\mathrm{M}=\mathrm{Fe}, \mathrm{Mn}$, Co or Ni) are very attractive as cathode materials for LIBs. $\mathrm{LiMPO}_{4}$ has an olivine structure, Fig. 9, and crystallizes in the orthorhombic Pnma space group in which the oxygen ions form a hexagonal closepacked framework, Li occupies the octahedral M1 site (4a) forming a tunnel along the direction [010], the transition metal (Fe, Ni, Mn, or Co) ion is located in the M2 site (4c) forming a zigzag chain of corner shared octahedra linked to the phosphate tetrahedra. The $\mathrm{MO}_{6}$ octahedral and $\mathrm{PO}_{4}$ tetrahedral share their edges. The strong $\mathrm{P}-\mathrm{O}$ covalent bond provides high thermodynamic stability and prevents oxygen evolution at high temperatures compared to $\mathrm{LiCoO}_{2}$ and $\mathrm{LiNiO}_{2}$. This strong $\mathrm{PO}_{4}{ }^{3-}$ shows lower redox energy of $3 \mathrm{~d}$ orbital of the metal than the Fermi level. Therefore, the $\mathrm{P}-\mathrm{O}$ covalent bond is responsible for the lower potential in olivine than oxide materials. The cell parameters of $\mathrm{LiMPO}_{4}(\mathrm{M}=\mathrm{Fe}, \mathrm{Mn}, \mathrm{Co}$, or Ni) are given in Table 5.

6.1.1 $\mathrm{LiFePO}_{4} \cdot \mathrm{LiFePO}_{4}$ is the most attractive commercialized cathode material because of its desirable safety features, high theoretical capacity $\left(170 \mathrm{~mA} \mathrm{~h} \mathrm{~g}{ }^{-1}\right)$ at moderate current densities, stable $\mathrm{Fe}^{3+} / \mathrm{Fe}^{4+}$ redox potential of $3.5 \mathrm{~V} v s . \mathrm{Li}^{+} / \mathrm{Li}$, flat voltage plateau, thermal stability even at high temperatures, stable electrochemical and chemical properties, excellent cycling performance, low cost, and abundance of iron. During the insertion and removal of $\mathrm{Li}^{+}$, it was observed that there are two coexisting phases, $\mathrm{LiFePO}_{4}$ and $\mathrm{FePO}_{4}$. Both phases have the same space group (Pnma). Padhi et al. suggested that the insertion and extraction of $\mathrm{Li}^{+}$is associated with the motion of the two-phase interface. ${ }^{111}$ They suggested the shrinkage core model in which the Li ions move from the surface of a particle inward through the phase boundary. Upon lithiation, the surface area of the interface decreases until it reaches a critical surface area when the rate of $\mathrm{Li}$ insertion is not able to sustain the applied current. This makes $\mathrm{LiFePO}_{4}$ a suitable material for low power applications as it influences the performance of the material in terms of capacity and rate capability at high current density. Srinivasan et al. assumed a juxtaposition of the $\mathrm{LiFePO}_{4}$ and $\mathrm{FePO}_{4}$ phases and suggested a shrinking core model in which the shell of one phase covers the core of the other phase by considering that the Li-ion diffusion drives the phase boundary motion. ${ }^{112}$

The battery cycling and calendar age influence the cycle life, capacity, and power capability of LIB. The factors that influence the performance can be a function of either the operation conditions, such as temperature or working potential window,
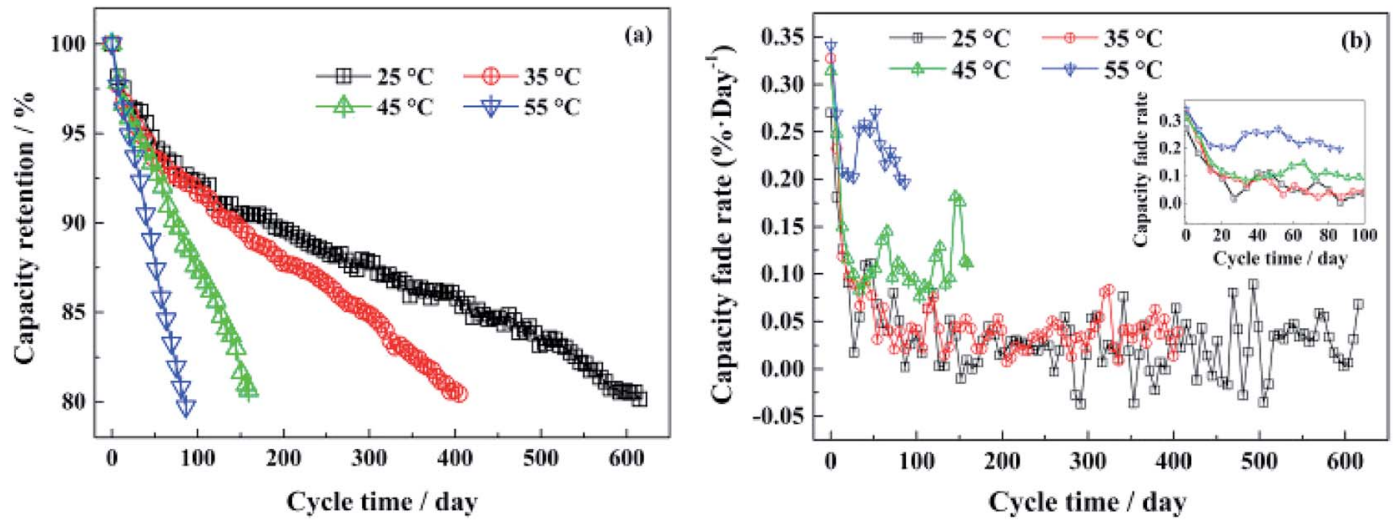

Fig. 10 (a) The capacity retentions of the $\mathrm{LiFePO}_{4} /$ graphite full cells at different temperatures with continuous cycling days, (b) the capacity fade rate at each test temperature during cycling. ${ }^{113}$ 

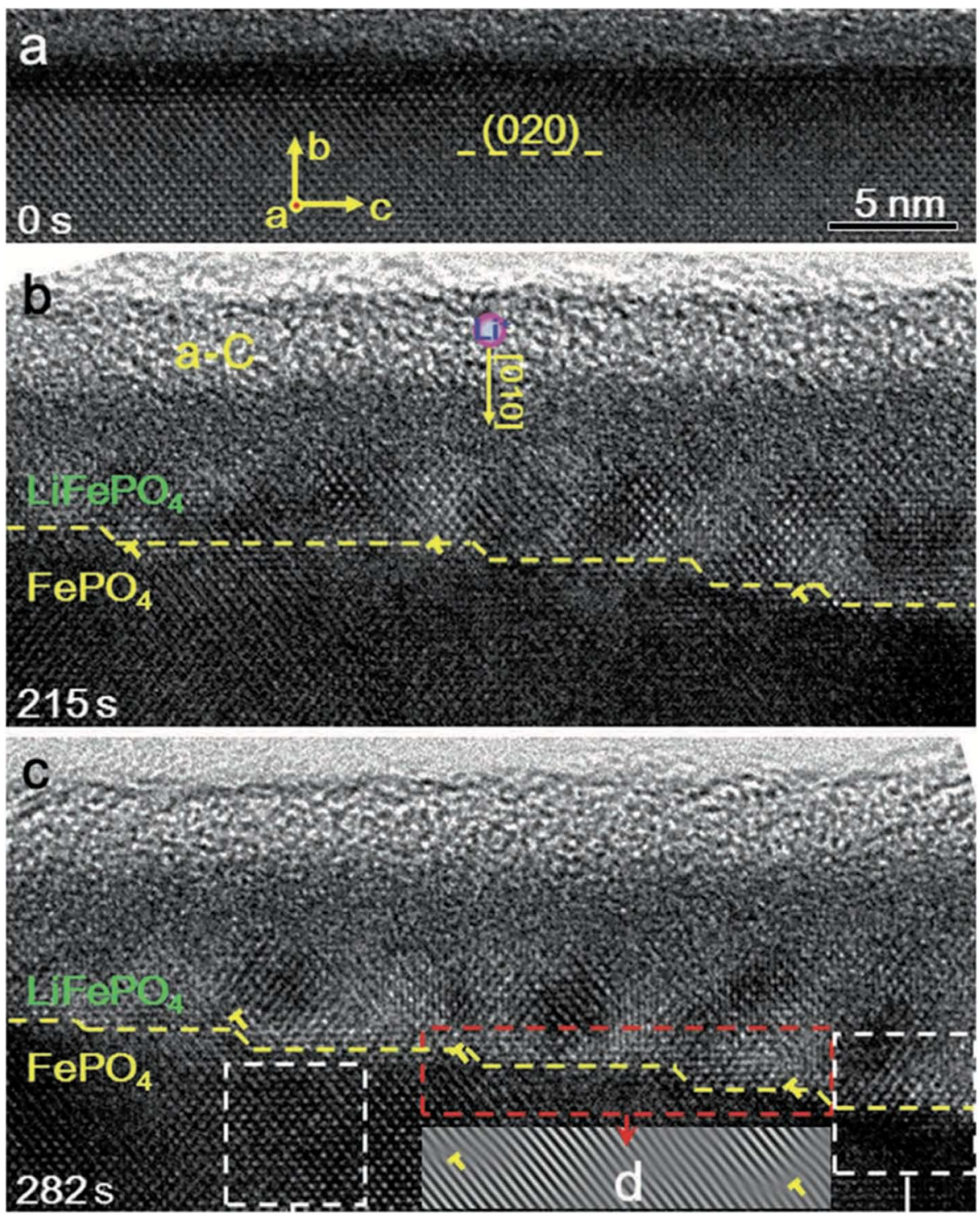

Fig. 11 Phase boundary between $\mathrm{FePO}_{4}$ and $\mathrm{LiFePO}_{4}$ and its migration along the [010] direction during lithiation. (a) A HRTEM image of the pristine $\mathrm{FePO}_{4}$ (b) after 215 second from applying the voltage, a step-like phase boundary was formed between $\mathrm{FePO}_{4}$ and $\mathrm{LiFePO}_{4}$, as pointed out by the yellow dashed line. (c) At 282 seconds, the thickness of the $\mathrm{LiFePO}_{4}$ layer increased as the step-like phase boundary propagating along the [010] direction. ${ }^{114}$

or the type of the cathode material. For example, Sun et al. showed that the high temperature to have a tremendous negative impact on the performance of the $\mathrm{LiFePO}_{4}$ battery. ${ }^{113}$ The battery lifetime at room temperature is about seven times higher than that at $55^{\circ} \mathrm{C}$ as presented in Fig. 10. The reason for capacity loss at room temperature is assigned to the irreversible loss of $\mathrm{Li}$ by the formation of a solid electrolyte interface (SEI) layer. Upon increasing the ambient temperature, the interplanar spacing between the crystallographic planes of the structure becomes larger, and the surface layer (SEL) becomes thicker, which is a sign of degradation. Also, the SEM images of the surface of the aged cathodes at temperatures higher than $45{ }^{\circ} \mathrm{C}$ showed a rounded-shaped particle rich in fluorine with the particle size increased from $0.7-0.8 \mu \mathrm{m}$ to $1.3-1.5 \mu \mathrm{m}$ with increasing the temperature, which is accompanied by the accelerated decomposition of the electrolyte.

There is a structural instability that usually occurs during the intercalation and de-intercalation process of $\mathrm{Li}$, which results in fast capacity fading upon cycling. A study used in situ TEM and HRTEM analyses showed that the lithiation and de-lithiation in $\mathrm{LiFePO}_{4}$ occur by two phase reactions $\left(\mathrm{LiFePO}\right.$ and $\left.\mathrm{FePO}_{4}\right){ }^{\mathbf{1 1 4}}$ Upon applying potential to $\mathrm{FePO}_{4}$, Li ions inserted into the structure to form a layer of $\mathrm{LiFePO}_{4}$ that gets thicker with time, which was evident via the migration of the step shape phase boundary along the $b$ axis or [010] direction as shown in Fig. 11. This study proves that there is a lattice mismatch that induced dislocation at the phase boundary, where the transformation between the two phases produced an array of dislocations in the $\mathrm{FePO}_{4}$ side. Also, the orientation of $\mathrm{LiFePO}_{4}$ changed slightly 
(a)

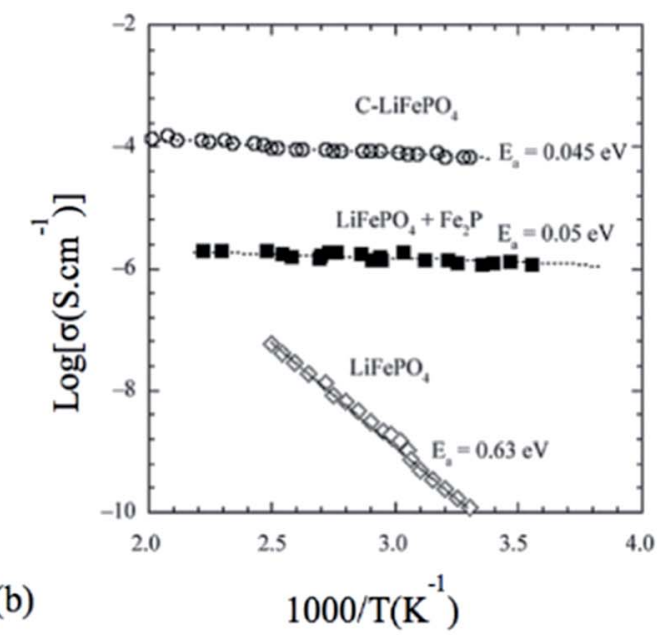

(c)
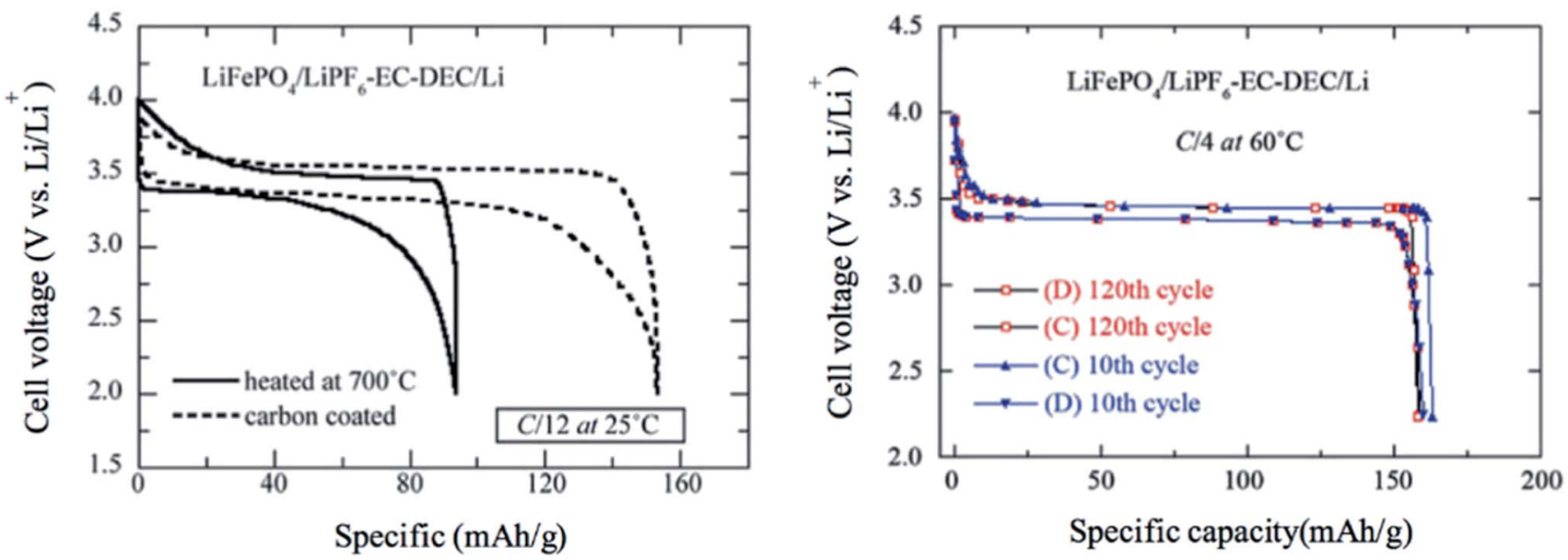

Fig. 12 (a) Electronic conductivity of pure $\mathrm{LiFePO}_{4}, \mathrm{Fe}_{2} \mathrm{P}$-containing sample and $\mathrm{C} / \mathrm{LiFePO}_{4}$. (b) The electrochemical profiles at $\mathrm{C} / 12$ of noncoated and heated at $700^{\circ} \mathrm{C} \mathrm{LiFePO} / / / \mathrm{Li}$ cells (c) electrochemical performance of the $\mathrm{C}-\mathrm{LiFePO}_{4} / / \mathrm{Li}$ cell operating at $60^{\circ} \mathrm{C}$. Charge-discharge cycling was conducted at the $\mathrm{C} / 4$ rate (about $35 \mathrm{~mA} \mathrm{~g}^{-1}$ ) in the voltage range $2.2-4.0 \mathrm{~V} \mathrm{vs.} \mathrm{Li}^{0} / \mathrm{Li}^{+} .{ }^{123}$

compared to $\mathrm{FePO}_{4}$ as a result of the elastic deformation that can accommodate the transformation strain. These dislocations accumulate during the cycling and can cause further defects/ cracks that cause degradation. Moreover, the ageing of $\mathrm{C}_{6} /$ $\mathrm{LiFePO}_{4}$ (LFP) batteries was studied theoretically by the electron-tunneling-based model for lithium immobilization. ${ }^{115}$ The SEI formation model presumes the existence of a porous outer and dense inner SEI layers. Electron tunneling through the inner SEI layer is considered to be the rate-determined step in the SEI formation process and its initial thickness after activation process controls the degradation rate. The outer SEI layer grows much faster than the inner layer. During cycling, cracks formation takes place, exposing the new surface of graphite to the electrolyte directly resulting in the formation of SEI, hence loss in capacity. The formed SEI was found to be dependent on the number of cycles.

$\mathrm{LiFePO}_{4}$ has a low intrinsic electronic conductivity of $10^{-9} \mathrm{~S} \mathrm{~cm}^{-1}$ and low ionic conductivity. Several attempts were carried out to increase both its ionic and electronic conductivity and, consequently, its electrochemical performance. First, conductive surface coating by carbon was found to improve the electronic conductivity due to the improved electric contact between the electrode particles, as shown in Fig. 12a. ${ }^{116}$ Several groups tailored the $\mathrm{C} / \mathrm{LiFePO}_{4}$ composite electrode and obtained specific capacity close to the theoretical limits of $\mathrm{LiFePO}_{4}$ (170 $\mathrm{mA} \mathrm{h} \mathrm{g}^{-1}$ ). Furthermore, C-coating prevents particle growth during heat treatment resulting in the synthesis of smaller particle size and higher surface area $\mathrm{LiFePO}_{4} \cdot{ }^{117} \mathrm{Fig} .12 \mathrm{~b}$ shows a comparison between the electrochemical profile of the bare and C-coated $\mathrm{LiFePO}_{4}$ at $\mathrm{C} / 12$ rate; both have the same particle size $(40 \mathrm{~nm})$. The C-coated sample showed high capacity that is close to the theoretical limit, while bare $\mathrm{LiFePO}_{4}$ showed only $55 \%$ of the theoretical capacity. Even at higher rate of $\mathrm{C} / 4, \mathrm{C} / \mathrm{LiFePO}_{4}$ shows excellent $\mathrm{Li}$ ions extraction kinetics and outstanding ability to maintain $100 \%$ of its initial capacity $\left(160 \mathrm{~mA} \mathrm{~h} \mathrm{~g}^{-1}\right)$ after 120 cycles. However, the addition of additives such as $\mathrm{C}$ would increase the conductivity, but it decreases the energy density of the cathode because it is counted as electrochemical inactive material. Carbon-free $\mathrm{LiFePO}_{4}$ small particles with narrow size distribution can 
shorten the ionic and electronic diffusion length and improve the conductivity of the material. ${ }^{118,119}$ Delacourzt et al. prepared 100-200 nm $\mathrm{LiFePO}_{4}$, which showed a high reversible specific capacity of $145 \mathrm{~mA} \mathrm{~h} \mathrm{~g}{ }^{-1}$ at $\mathrm{C} / 2$. Third, the electronic conductivity and $\mathrm{Li}$ ion diffusion in $\mathrm{LiFePO}_{4}$ structure would be improved by doping at the anionic and/or cationic sites. Chung et al. reported that multivalent ions-doped $\mathrm{LiFePO}_{4}$ showed outstanding electronic conductivity of eight orders of magnitude higher than pure $\mathrm{LiFePO}_{4}{ }^{120}$ However, the reason for the improved conductivity is questioned since Herle et al. ${ }^{121}$ showed that the iron salt precursor in Chung's experiment was the source of $\mathrm{C}$, which can reduce $\mathrm{Fe}$ and $\mathrm{P}$ to $\mathrm{Fe}_{2} \mathrm{P}$ and/or $\mathrm{Fe}_{3} \mathrm{P}$ (conductivity of $\mathrm{LiFePO}_{4}+\mathrm{Fe}_{2} \mathrm{P}$ is shown in Fig. 12a). Therefore, the metal-rich phosphides are believed to be responsible for the improved conductivity. A combination of $\mathrm{C}$ and $\mathrm{Zn}^{4+}$ doping showed a synergetic effect that facilitated electron transport. ${ }^{122}$
6.1.2 $\mathrm{LiMnPO}_{4}$. The low energy density of $\mathrm{LiFePO}_{4}$ restricts their use in the automotive industry. The study and development of other members from the olivine family with higher discharge voltage and energy density, such as $\mathrm{LiMnPO}_{4}$, are critical. $\mathrm{LiMnPO}_{4}$ showed higher potential than $\mathrm{LiFePO}_{4}(4.1 \mathrm{~V}$ vs. $\left.\mathrm{Li}^{0} / \mathrm{Li}^{+}\right)$and a high energy density of $\sim 700 \mathrm{~W} \mathrm{~h} \mathrm{~kg}{ }^{-1} \cdot{ }^{124}$ However, cyclic stability and rate capability of $\mathrm{LiMnPO}_{4}$ are hindered by the poor kinetics and low ionic and electronic conductivity. Furthermore, the presence of $\mathrm{Mn}^{3+}$ ions in an unstable position in the lattice leads to cell distortion, which is controlled by the Jahn-Teller effect. ${ }^{125}$ Similar to $\mathrm{LiFePO}_{4}$, several strategies were used to improve the conductivity of $\mathrm{LiMnPO}_{4}$, such as the synthesis of smaller particle size, carbon coating, and cation substitution by $\mathrm{Fe}, \mathrm{Mg}$, or $\mathrm{Zn} .{ }^{126-128}$ The solid solution of $\mathrm{LiMnPO}_{4}$ and $\mathrm{LiFePO}_{4}$ operates in the voltage range between 3.4 and $4 \mathrm{~V} v s$. $\left(\mathrm{Li} / \mathrm{Li}^{+}\right)$, which is not very high to prevent
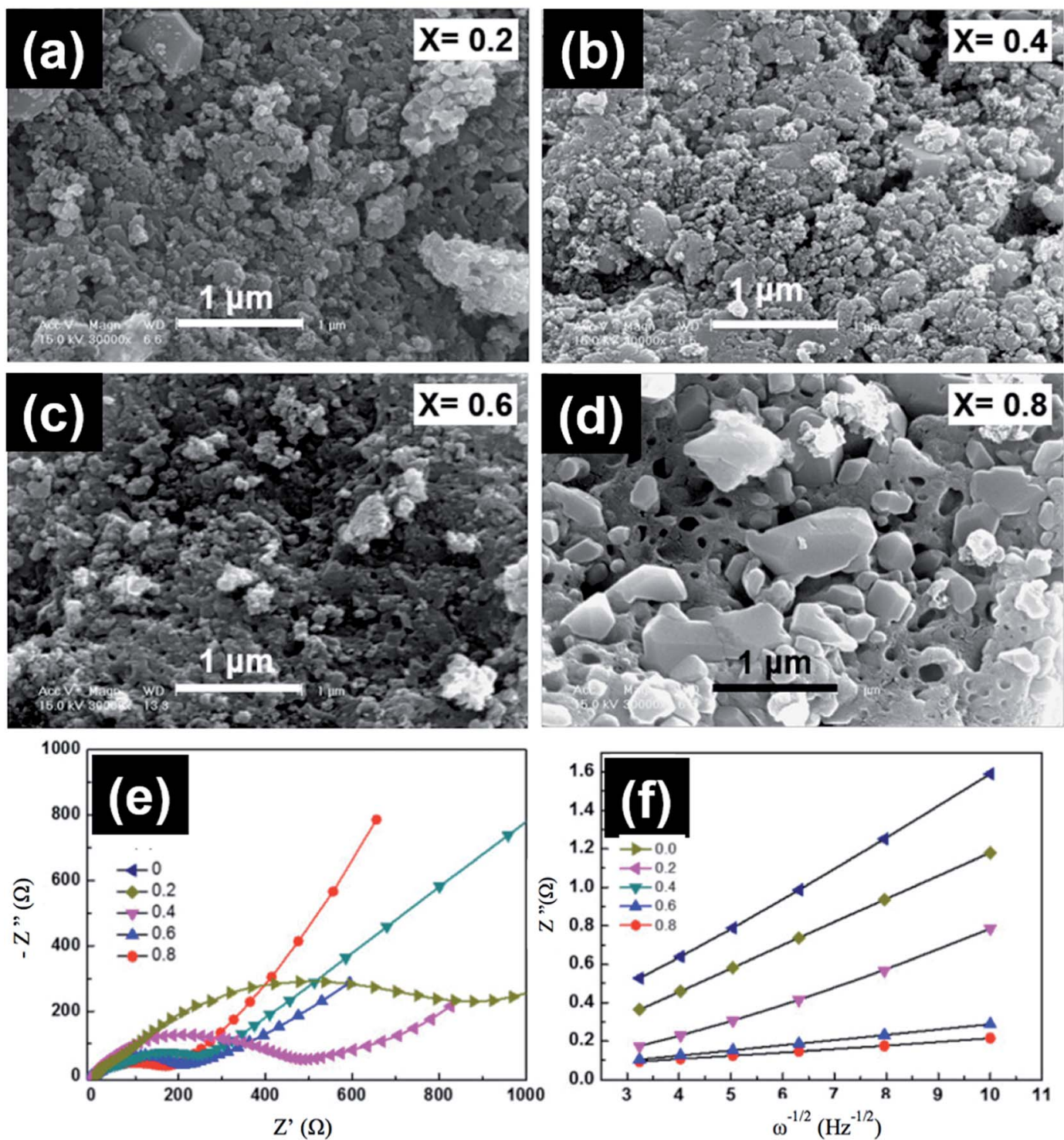

Fig. $13(a-d)$ FESEM images, (e) impedance spectra, and (f) the relationship between $Z^{\prime \prime}$ and the square root of frequency ( $\left.\omega^{-1 / 2}\right)$ in the lowfrequency region for $\mathrm{LiMn}_{1-x} \mathrm{Fe}_{x} \mathrm{PO}_{4}$ at different compositions. ${ }^{131}$ 

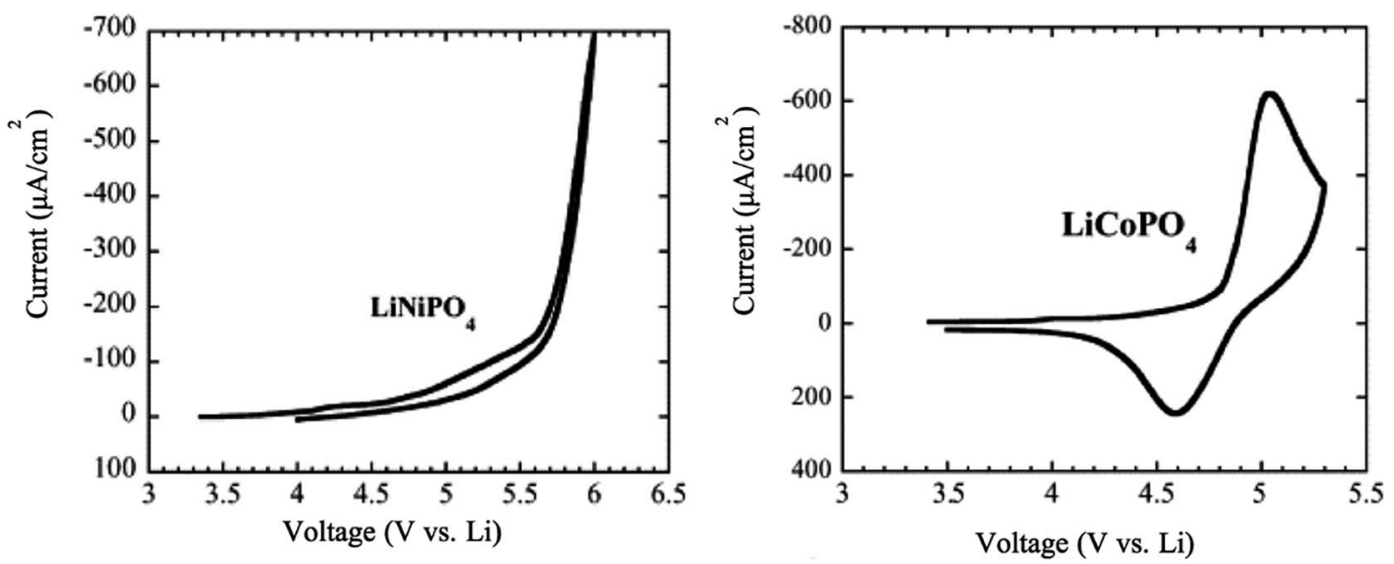

Fig. 14 Cyclic voltammetry of $\mathrm{LiNiPO}_{4}$ and $\mathrm{LiCoPO}_{4}$ at a scan rate of $0.2 \mathrm{mV} \mathrm{s}^{-1} .135$

the electrolyte decomposition and at the same time offers high energy density with respect to $\mathrm{LiFePO}_{4}$ and better rate capability than $\mathrm{LiMnPO}_{4} \cdot{ }^{129} \mathrm{~A}$ common defect of anti-site mixing between $\mathrm{Fe} / \mathrm{Mn}$ and $\mathrm{Li}$ ions in the mixed LMFP is dependent on the synthesis method, and it affects the Li ions motion along the 010 channel upon cycling. Sun et al. ${ }^{130}$ studied the effect of Fe substitution on the conductivity and $\mathrm{Mn}$ ions dissolution. They prepared nanostructured $\mathrm{LiFe}_{x} \mathrm{Mn}_{1-x} \mathrm{PO}_{4}(x=0$ and 0.15$)$ by

(a)
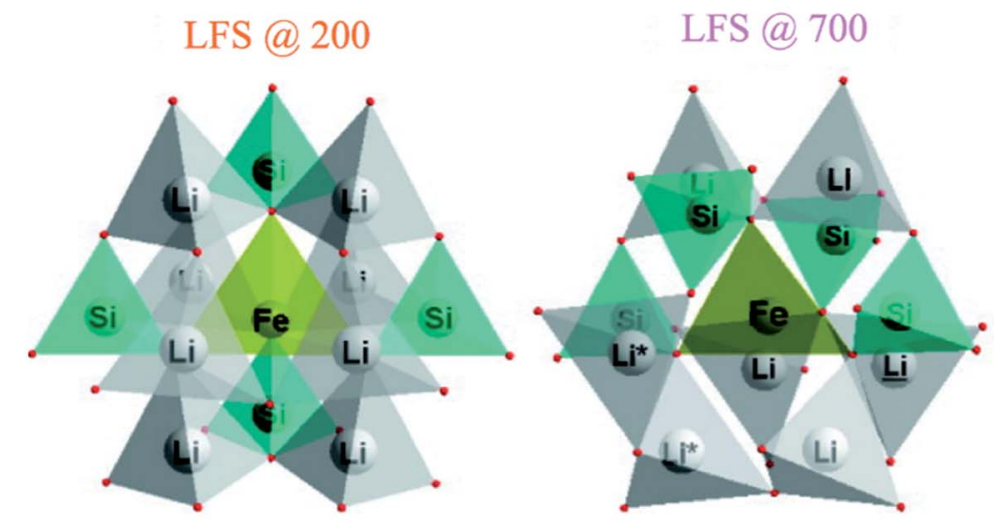

LFS@900

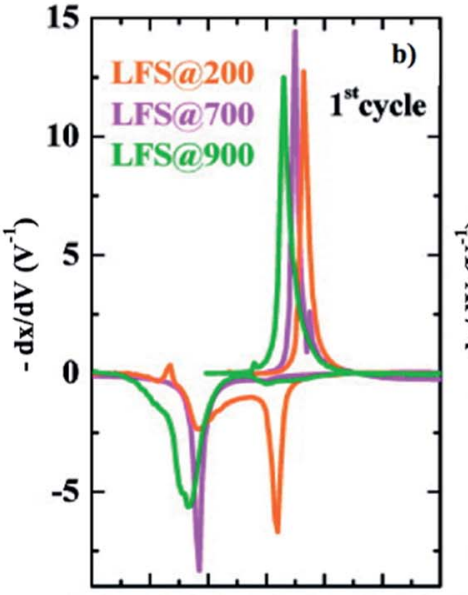

2.42 .62 .83 .03 .23 .43 .6 $\mathrm{U}\left(\mathrm{v} \mathrm{VS} . \mathrm{Li}^{+} / \mathrm{Li}^{0}\right)$
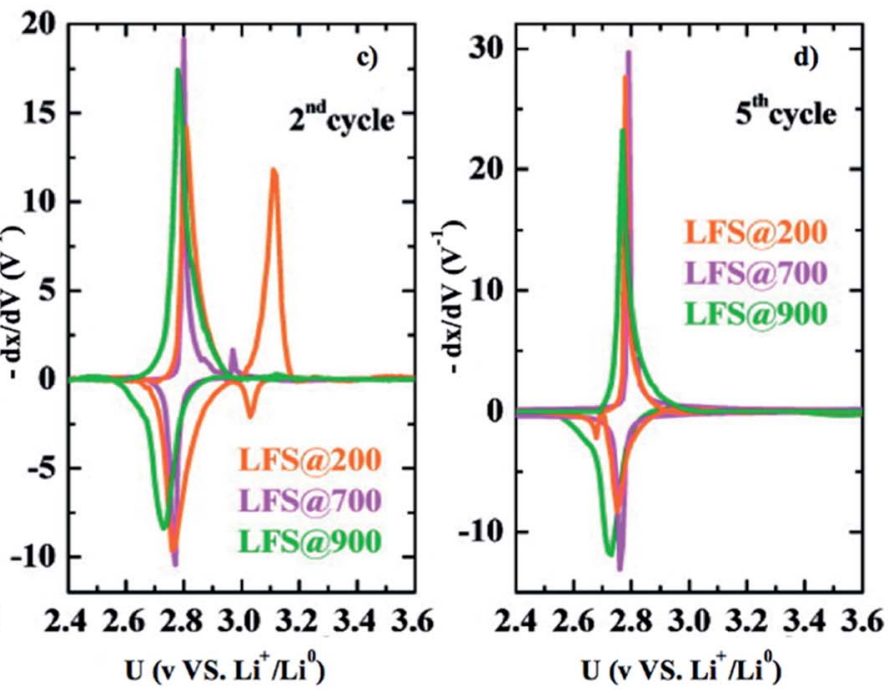

Fig. 15 (a) The three polymorphs of $\mathrm{Li}_{2} \mathrm{FeSiO}_{4}$, derivative plots obtained from PITT measurements in the (b) first, (c) second, and (d) fifth cycles for all three polymorphs. ${ }^{141}$ 
spray pyrolysis and suggested that the performance was improved because the conductivity increased, and Mn dissolution decreased from 103.7 to $87.2 \mathrm{ppm}$. Seo et al. ${ }^{131}$ studied the charge transfer resistance $\left(R_{\mathrm{ct}}\right)$ and the electrochemical performance of $\mathrm{LiFe}_{x} \mathrm{Mn}_{1-x} \mathrm{PO}_{4}$ at $x=0,0.2,0.4,0.6,0.8$. The best electrochemical performance was observed when $x=0.8$ and 0.6 , which corresponded to the highest discharge capacity of almost 154 and $149 \mathrm{~mA} \mathrm{~h} \mathrm{~g}^{-1}$ and retained $100 \%$ and $101 \%$ of its initial capacity after 50 cycles, respectively. The impedance patterns of all compositions showed a single semicircle in the high frequency region as shown in Fig. 13. The semicircle at high frequencies is due to the combination between double layer capacitance and $R_{\mathrm{ct}}$. The $R_{\mathrm{ct}}$ decreased by increasing the Fe content and reached its lowest value of $170 \Omega$ when $x=0.8$. The Warburg impedance at low frequency is related to the diffusion of $\mathrm{Li}$ ions. The $\mathrm{Li}$ ions diffusion increased with decreasing the slope of the line and reached its highest value of $7.33 \times 10^{-14}$ when $x=0.8$. Dai et al. reported that the co-substitution of Mn by $\mathrm{Fe}$ and $\mathrm{Mg}$ could significantly improve the cycling performance, where the optimal composition was found to be $\mathrm{LiMn}_{0.8} \mathrm{Fe}_{0.19} \mathrm{Mg}_{0.01} \mathrm{PO}_{4} \cdot{ }^{132}$ Moreover, they studied the effect of $\mathrm{C}$ content on the electrochemical performance of this composition. The material with $10.5 \mathrm{wt} \%$ carbon showed the best rate capability and capacity of $143.1 \mathrm{~mA} \mathrm{~h} \mathrm{~g}{ }^{-1}, 130 \mathrm{~mA} \mathrm{~h} \mathrm{~g}{ }^{-1}$, and $125.7 \mathrm{~mA} \mathrm{~h} \mathrm{~g}^{-1}$ at $1 \mathrm{C}, 5 \mathrm{C}$, and $10 \mathrm{C}$ rates, respectively. Lower $\mathrm{C}$ content of $4.1 \mathrm{wt} \%$ showed a slight decrease in the rate capability. However, further decrease or increase in the $\mathrm{C}$ content to $2 \mathrm{wt} \%$ or $27.4 \mathrm{wt} \%$ resulted in fast capacity fade at high $\mathrm{C}$ rate. ${ }^{\mathbf{1 3 3}}$ This better performance is explained by the lowest charge transfer resistance of $\sim 27 \Omega$ at $10 \mathrm{wt} \% \mathrm{C}$ electrodes.

6.1.3 $\mathrm{LiCoPO}_{4}$ and $\mathrm{LiNiPO}_{4}$. The $\mathrm{LiCoPO}_{4}$ and $\mathrm{LiNiPO}_{4}$ materials exhibit a high potential of $4.8 \mathrm{~V}$ and $5.2-5.4 \mathrm{~V}$, respectively. ${ }^{134}$ It is challenging to extract lithium from $\mathrm{LiNiPO}_{4}$ within the stable voltage window of the available electrolytes. Moreover, both compounds showed much lower electronic

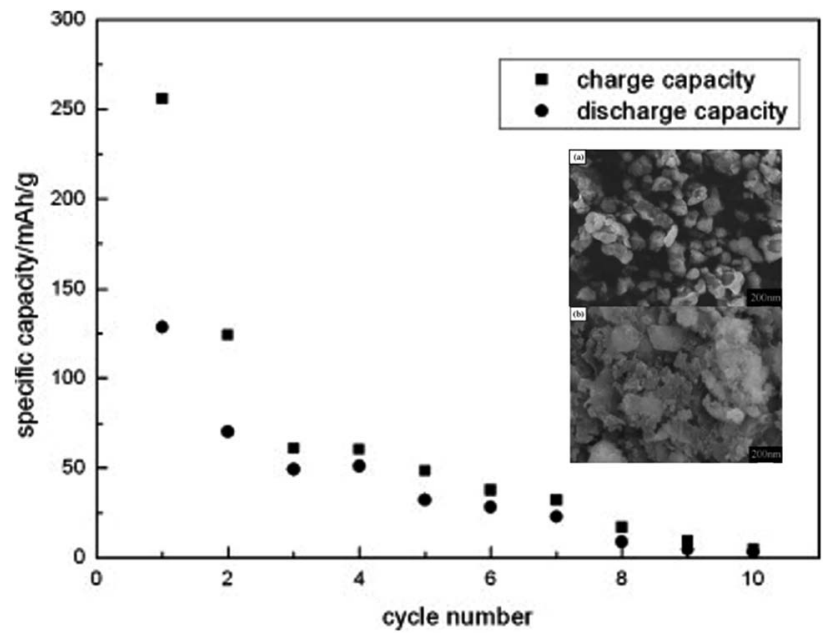

Fig. 16 Cyclic performance of $\mathrm{Li}_{2} \mathrm{MnSiO}_{4}$ synthesized by solid state method tested at $\mathrm{C} / 16$ rate to a cut-off voltage between 1.5 and $4.8 \mathrm{~V} .{ }^{152}$ The inset shows FESEM micrographs of (a) $\mathrm{Li}_{2} \mathrm{MnSiO}_{4}$ and (b) $\mathrm{Li}_{2} \mathrm{MnSiO}_{4} / \mathrm{C}$. conductivity than LFP and LMP. The cyclic voltammetry of $\mathrm{LiCoPO}_{4}$ showed that there is a reduction peak at $4.6 \mathrm{~V}$ and an oxidation peak at $5.1 \mathrm{~V}$, while there are no significant reduction peaks for $\mathrm{LiNiPO}_{4}$ in the range between 3.5 to $6 \mathrm{~V} v s . \mathrm{Li} / \mathrm{Li}^{+}$as shown in Fig. 14. ${ }^{135}$

\subsection{Silicate-based cathode materials}

The replacement of phosphate by silicate was a crucial step in the search for new high energy cathode materials. Orthosilicate cathode materials $\left(\mathrm{Li}_{2} \mathrm{MSiO}_{4}, \mathrm{M}=\mathrm{Fe}, \mathrm{Mn}\right)$ are of particular interest due to their superior electrochemical performance, safety, raw material abundance, and low cost. $\mathrm{Li}_{2} \mathrm{MSiO}_{4}$ has a high theoretical specific capacity $\left(\sim 333 \mathrm{~mA} \mathrm{~h} \mathrm{~g}^{-1}\right)$ if the two Li ions are fully extracted per formula unit. Several temperatures and pressure-dependent polymorphs of $\mathrm{Li}_{2} \mathrm{MSiO}_{4}$ exist. ${ }^{136}$ The framework consists of distorted hexagonal close backed oxygen array, and all cations occupy tetrahedral sites. The different possible cations ordering produce different polymorphs. These polymorphs can be divided into low or high temperature, which corresponds to $\beta$ or $\gamma \mathrm{Li}_{3} \mathrm{PO}_{4}$ like structures, respectively. Each type could be explained in several space groups such as orthorhombic $\beta_{\mathrm{I}}\left(P b n 2_{1}, P n a 2_{1}\right)$ and $\beta_{\mathrm{II}}\left(P m n 2_{1}\right)$, monoclinic $\gamma_{\mathrm{s}} / \gamma_{0}$ $\left(P 2_{1} / n\right)$, and orthorhombic $\gamma_{\mathrm{II}}$ (Pmna, Pmnb).

6.2.1 $\mathrm{Li}_{2} \mathrm{FeSiO}_{4} \cdot \mathrm{Li}_{2} \mathrm{FeSiO}_{4}$ exhibits a specific capacity of $166 \mathrm{~mA} \mathrm{~h} \mathrm{~g}{ }^{-1}$ since only one $\mathrm{Li}^{+}$can be extracted due to the redox couple $\mathrm{Fe}^{3+} / \mathrm{Fe}^{2+}$ at $3.1 \mathrm{~V}$ vs. $\mathrm{Li}^{+} / \mathrm{Li}$. The lower electronegativity of $\mathrm{Si}$ compared to $\mathrm{P}$ results in a lowering of the $\mathrm{Fe}^{3+} / \mathrm{Fe}^{2+}$ redox couple in $\mathrm{Li}_{2} \mathrm{FeSiO}_{4}$ than in $\mathrm{LiFePO}_{4}$. The other redox couple $\mathrm{Fe}^{4+} / \mathrm{Fe}^{3+}$ takes place at a high voltage of 4.85 , which is outside the stability window of the electrolyte; therefore, it is not reached. $\mathrm{Li}_{2} \mathrm{FeSiO}_{4}$ exhibits complex structural defects that make it difficult to analyze its structure. Nytén et al. ${ }^{137}$ reported $\mathrm{Li}_{2} \mathrm{FeSiO}_{4}$ in the orthorhombic system with $P m n 2_{1}$ space group and explained two additional peaks in its diffractogram as an unidentifiable impurity. Its potential shifts irreversibly from $3.1 \mathrm{~V}$ to $2.8 \mathrm{~V}$ in the second cycle. This voltage drop was

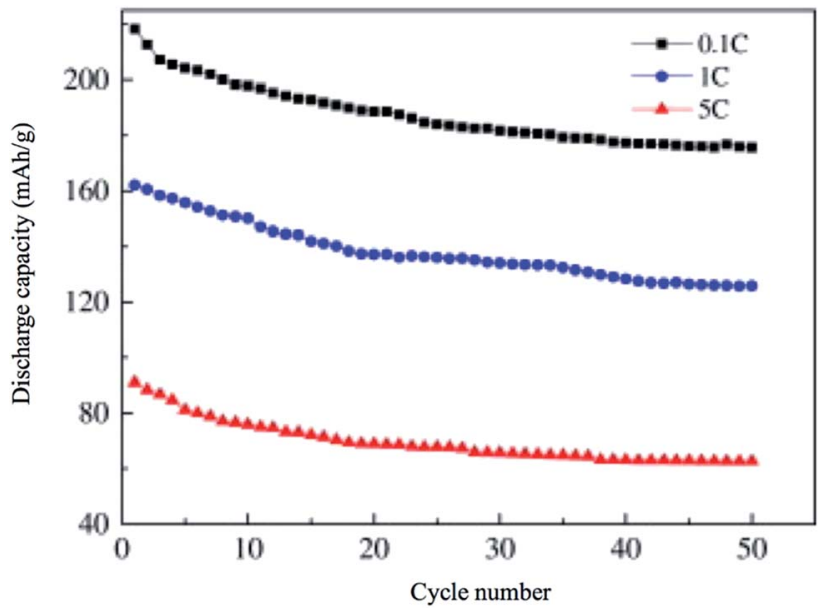

Fig. 17 Cyclic performance of nano $\mathrm{C} / \mathrm{Li}_{2} \mathrm{MnSiO}_{4}$ synthesized by ionothermal method, the material is tested in the potential range of $2.5-4.5 \vee .^{153}$ 


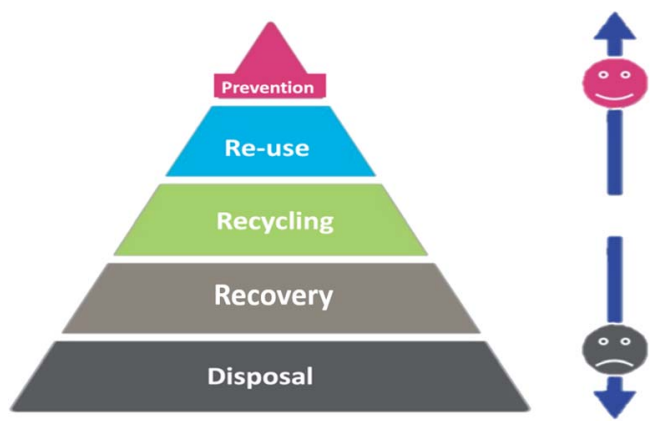

Fig. 18 The waste management hierarchy and range of recycling options. ${ }^{158}$

suggested to be due to site mixing between $\mathrm{Li}$ ions and Fe ions since the $\mathrm{Li}: \mathrm{Fe}$ ratio in the $4 \mathrm{~b}$ site changed from $96: 4$ to 40 : 60 during the first cycle. ${ }^{138}$ Nishimura et al. ${ }^{139}$ reported $\mathrm{Li}_{2} \mathrm{FeSiO}_{4}$ in the monoclinic system and $P 2_{1}$ space group. Sirisopanaporn et al. ${ }^{\mathbf{1 4 0}}$ synthesized a polymorph, which is an isostructural with $\mathrm{Li}_{2} \mathrm{CdSiO}_{4}$ and is described by the Pmnb space group. Sirisopanaporn et al. ${ }^{\mathbf{1 4 1}}$ compared the electrochemical behavior of $\mathrm{Li}_{2} \mathrm{FeSiO}_{4}$ polymorphs, which were explained in the $P m n 2_{1}, P 2_{1} / n$, and $P m n b$ space groups by synthesis under hydrothermal conditions at 200,700 , and $900{ }^{\circ} \mathrm{C}$, respectively. The structural difference of these polymorphs is shown in Fig. 15a. Each polymorph showed different first oxidation potential. The Pmnb polymorph exhibited the lowest potential $\left(2.9 \mathrm{~V} v s . \mathrm{Li}^{+} / \mathrm{Li}^{0}\right), P 2_{1} / n$ showed an intermediate potential of 2.97 vs. $\mathrm{Li}^{+} / \mathrm{Li}^{0}$, while $P m n 2_{1}$ showed the highest oxidation potential $\left(3.1 \mathrm{~V} v s . \mathrm{Li}^{+} / \mathrm{Li}^{0}\right)$. Derivative plots obtained from PITT of the three polymorphs showed that they all experience the voltage fade from 3 to $2.8 \mathrm{~V}$ upon cycling due to the transformation to Li-poor phase as shown in Fig. 15b-d. More precisely, it showed that the high temperature $P m n b$ and $P 2_{1} / n$, which have high degree of disorder, transformed faster than the low temperature $P m n 2_{1}$. The first discharge reduction potential of $P m n b$ and $P 2_{1} / n$ was $\sim 2.76 \mathrm{~V} v s . \mathrm{Li}^{+} / \mathrm{Li}^{0}$, while the discharge of

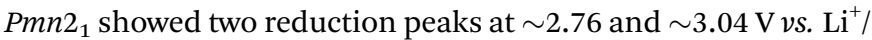
$\mathrm{Li}^{0}$ indicating the presence of initial $\mathrm{Li}_{2} \mathrm{FeSiO}_{4}$. The hightemperature $P m n b$ and $P 2_{1} / n$ experienced a phase transformation at the first cycle faster than $P m n 2_{1}$, which is fully transformed at the fifth discharge.

6.2.2 $\mathrm{Li}_{2} \mathrm{MnSiO}_{4} \cdot \mathrm{Li}_{2} \mathrm{MnSiO}_{4}$ is a more interesting material than $\mathrm{Li}_{2} \mathrm{FeSiO}_{4}$ as it offers higher redox potential and specific capacity. $\mathrm{Li}_{2} \mathrm{MnSiO}_{4}$ possesses a theoretical capacity of $333 \mathrm{~mA} \mathrm{~h} \mathrm{~g}{ }^{-1}$ because of the contribution of two Li ions to the electrochemical reaction. This is because $\mathrm{Mn}$ ions can be reversibly oxidized and reduced from the +2 state to +4 state with the redox couples of $\mathrm{Mn}^{2+} / \mathrm{Mn}^{3+}$ and $\mathrm{Mn}^{3+} / \mathrm{Mn}^{4+}$ at 4.1 and $4.5 \mathrm{~V}$ vs. $\mathrm{Li}^{+} / \mathrm{Li}$, respectively. At $0 \mathrm{~K}$, the low-temperature $\beta$ $\mathrm{Li}_{3} \mathrm{PO}_{4}$ is more thermodynamically stable than the hightemperature $\gamma-\mathrm{Li}_{3} \mathrm{PO}_{4}$. The transformation from $\beta$ to $\gamma$ structures is exothermic and can take place at higher temperatures. Also, the $\gamma$ to $\beta$ transformation can happen under high-pressure conditions. ${ }^{142}$ The separation of polymorphs is possible by applying the preferred conditions of each structure. $P 2_{1} / n$ is

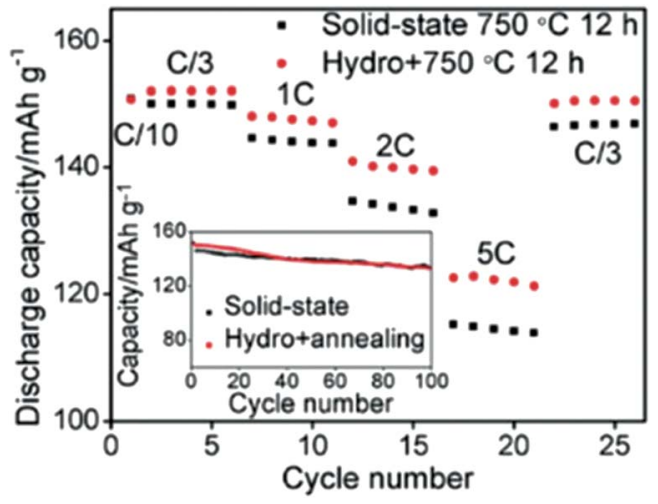

Fig. 19 Comparison of two materials, one was sintered for $12 \mathrm{~h}$ at $750{ }^{\circ} \mathrm{C}$ and the other was prepared by hydrothermal method then sintered for $12 \mathrm{~h}$ at $750{ }^{\circ} \mathrm{C} .159$

obtained by synthesis at high temperatures, followed by fast quenching. The synthesis of $P m n 2_{1}$ polymorph is possible by controlling both the pressure and temperature at 2-8 GPa and 600-900 ${ }^{\circ} \mathrm{C}$, respectively. ${ }^{142}$ Among these polymorphs, the lowtemperature orthorhombic $P m n 2_{1}$ is the best polymorph as it shows favorable thermodynamic stability and exhibits the lowest $\mathrm{Li}$ diffusion energy barrier. $\mathrm{Li}_{2} \mathrm{MnSiO}_{4}$ suffers from poor performance and fast capacity fading problems upon cycling, as shown in Fig. 16. This is because of the low ionic and electronic conductivity $\left(\sim 5 \times 10^{-16} \mathrm{~S} \mathrm{~cm}^{-1}\right.$ at RT) ${ }^{143}$ and the structural instability due to the presence of $\mathrm{Mn}$ ions in the tetrahedral sites. Several strategies were proposed to improve its structural stability upon cycling. The synthesis of new polymorphs in which the Mn ions are sitting in stable octahedral sites was tested under high pressure up to $15 \mathrm{GPa}$. However, it was not obtained because of the strong cationic repulsion in the dense structures. ${ }^{\mathbf{1 4 4 , 1 4 5}}$ The addition of conductive carbon, such as acetylene black, showed significantly improved performance. ${ }^{\mathbf{1 4 6}}$ Nano $\mathrm{C} / \mathrm{Li}_{2} \mathrm{MnSiO}_{4}$ prepared by ionothermal method showed improved performance and capacity retention even at high $\mathrm{C}$ rates as shown in Fig. 17. Cation substitution by $\mathrm{Mg}, \mathrm{Ca}, \mathrm{Cr}$, $\mathrm{Ti}, \mathrm{V}, \mathrm{Ni}, \mathrm{Na}, \mathrm{Cu}$ or $\mathrm{P}$ improved the intrinsic conductivity and increased the Li ion diffusion coefficient. ${ }^{\text {147-151 }}$

\section{Go green with Li-ion batteries}

Following the growth of the Li-ion batteries industry, the environmental impact of such a technology is critical and must be carefully considered. Cathode materials are the key components in the battery in terms of cost and active weight. Their toxic byproducts during the manufacturing process as well as inadequate disposal ways, require urgent green approaches to avoid their severe health and environmental problems. One of the proposed methods in literature is to switch from conventional to green synthesis routs. To avoid environmental pollution and avert additional costs associated with processing the harmful byproducts that contain anions such as $\mathrm{Cl}^{-}, \mathrm{SO}_{4}{ }^{2-}, \mathrm{NO}_{3}{ }^{-}$, and gases like $\mathrm{N}_{x} \mathrm{O}_{y}, \mathrm{CO}$, and $\mathrm{NH}_{3} .{ }^{154}$ The electrochemical performance is one of the main factors that direct the industry, 
therefore, considering it side by side with the environmental issues is logical and crucial. As an example, Bolloju et al. obtained $165 \mathrm{~mA} \mathrm{~g}^{-1}$ at $0.1 \mathrm{C}$ from $\mathrm{LiFePO}_{4}$ prepared using $\mathrm{Fe}$ powder as a precursor, which is comparable to that obtained by conventional chemical synthesis. ${ }^{155}$ Fe powder is very advantageous over other precursors because it does not produce harmful anions. Also, there is a $100 \%$ atom economy delivered by the iron metal, which makes it cost-effective as well. Liu et al. prepared multi-doped $\mathrm{LiFePO}_{4} / \mathrm{C}$ with $\mathrm{Mn}$, Co, and Ni using Fe powder and spent electroless nickel plating solution. ${ }^{156}$ The product shows comparable performance to that obtained by the expensive ferrous oxalate or ferric oxide as well as to that prepared by conventional chemical routs.

Waste management is a process that considers the protection of the environment with various strategies in a hierarchy order (disposal, recovery, recycling, reuse, and prevention), as illustrated in Fig. 18. Accordingly, reusing a battery is cleaner than recycling because recycling needs to spend energy on transportation and processing. Thus, it is possible, for instance, to collect the batteries that retain $85 \%$ to $80 \%$ of their initial capacity from electric vehicles to reuse in stationary grid applications. ${ }^{157}$ Recycling can still help in decreasing pollution and satisfy the need for raw materials. Recycling relies first on the recovery of different streams of raw materials followed by a pyrometallurgical or hydrometallurgical process to extract metals ( $\mathrm{Li}, \mathrm{Ni}, \mathrm{Mn}, \mathrm{Al}, \mathrm{Cu}$ or $\mathrm{Co}$ ). Pyrometallurgical is simple; the battery is smelted in a high-temperature furnace to reduce the active materials into metallic alloy form and also produce slag and gases. ${ }^{\mathbf{1 5 8}}$ This method requires filters to trap the emitted toxic gases.

On the other hand, the hydrometallurgy process involves the leaching of the metal from the cathode by the use of aqueous solutions, such as a mixture of acid and hydrogen peroxide. Each metal can be obtained by extraction, precipitation, or electrodeposition. Shi et al. combined hydrothermal and annealing method to efficiently obtain $\mathrm{LiCoO}_{2}$ with controlled microstructure and composition and found that its rate capability is higher than that obtained by conventional solid-state synthesis (Fig. 19). ${ }^{159}$ Transition metals oxides and hydroxides were collected from commercial spent Li-ion batteries and used as a potential material for supercapacitors. ${ }^{\mathbf{1 6 0 , 1 6 1}}$ The battery cathode tapes were recycled and used as a catalyst for the degradation of the toxic methylene blue dye. ${ }^{\mathbf{1 6 2}}$

\section{Summary and outlook}

The use of different cathode materials, such as layered oxides, olivines, and spinels, for Li-ion batteries is summarized and discussed. The classification of these cathodes materials is based on the Li ion diffusion pathway in different structures. The principle challenge for Li-ion batteries is the development of functional materials that can offer higher energy, power, and lifetime than the currently existing materials. In order to achieve this goal, huge efforts were explored, including the development of Li-rich oxides or mixed transition metal layered oxides. Moreover, the origin of the factors affecting the battery lifetime, such as degradation of the materials upon cycling and aging, are of great importance as outlined in this review. Improving the performance of existing materials is possible through different strategies, including the creation of defects in the material, manipulation of nanostructured complexes, substitution with different transition metals, doping with foreign elements, and smart coatings. Furthermore, continued progress to safer batteries, clean green materials, and lower cost is required. To this end, modelling is a great tool to identify new cathode materials that can satisfy the balance between the electrochemical performance and environmental requirements. Moreover, recycling Li-ion batteries and recovery of their components to construct new devices should be adapted and widely investigated.

\section{Conflicts of interest}

There are no conflicts to declare.

\section{References}

1 K. Kariatsumari, H. Kume, H. Yomogita and P. Keys, Nikkei Electronics Asia, February, 2010.

2 J. Molenda, in Li-ion Batteries for Electric Vehicles, Annales Universitatis Mariae Curie-Sklodowska, De Gruyter Open Sp. z oo, 2011, p. 23.

3 http:/www.energystorageexchange.org/projects/ data_visualization, accessed May 10, 2020.

4 I. Yoon, S. Jurng, D. P. Abraham, B. L. Lucht and P. R. Guduru, Measurement of mechanical and fracture properties of solid electrolyte interphase on lithium metal anodes in lithium ion batteries, Energy Storage Materials, 2020, 25, 296-304.

5 S. J. An, J. Li, C. Daniel, D. Mohanty, S. Nagpure and D. L. Wood, The state of understanding of the lithiumion-battery graphite solid electrolyte interphase (SEI) and its relationship to formation cycling, Carbon, 2016, 105, 52-76.

6 P. Verma, P. Maire and P. Novák, A review of the features and analyses of the solid electrolyte interphase in Li-ion batteries, Electrochim. Acta, 2010, 55(22), 6332-6341.

7 Y. Zhou, M. Su, X. Yu, Y. Zhang, J.-G. Wang, X. Ren, R. Cao, W. Xu, D. R. Baer and Y. Du, Real-time mass spectrometric characterization of the solid-electrolyte interphase of a lithium-ion battery, Nat. Nanotechnol., 2020, 15(3), 224230.

8 G. M. Hobold, A. Khurram and B. M. Gallant, Operando Gas Monitoring of Solid Electrolyte Interphase Reactions on Lithium, Chem. Mater., 2020, 32(6), 2341-2352.

9 D. S. Adipranoto, T. Ishigaki, A. Hoshikawa, K. Iwase, M. Yonemura, K. Mori, T. Kamiyama, Y. Morii and M. Hayashi, Neutron diffraction studies on structural effect for Ni-doping in $\mathrm{LiCo}_{1-\mathrm{x}} \mathrm{Ni}_{\mathrm{x}} \mathrm{O}_{2}$, Solid State Ionics, 2014, 262, 92-97.

10 M. S. Whittingham, Lithium batteries and cathode materials, Chem. Rev., 2004, 104(10), 4271-4302.

11 J. Graetz, A. Hightower, C. C. Ahn, R. Yazami, P. Rez and B. Fultz, Electronic Structure of Chemically-Delithiated 
$\mathrm{LiCoO}_{2}$ Studied by Electron Energy-Loss Spectrometry, $J$. Phys. Chem. B, 2002, 106(6), 1286-1289.

12 J. N. Reimers and J. R. Dahn, Electrochemical and In Situ X-Ray Diffraction Studies of Lithium Intercalation in $\mathrm{Li}_{\mathrm{x}} \mathrm{CoO}_{2}$, J. Electrochem. Soc., 1992, 139(8), 2091-2097.

13 W.-S. Yoon, K.-B. Kim, M.-G. Kim, M.-K. Lee, H.-J. Shin, J.-M. Lee, J.-S. Lee and C.-H. Yo, Oxygen Contribution on Li-Ion Intercalation-Deintercalation in $\mathrm{LiCoO}_{2}$ Investigated by $\mathrm{O}$ K-Edge and Co L-Edge X-ray Absorption Spectroscopy, J. Phys. Chem. B, 2002, 106(10), 2526-2532.

14 Y. Jiang, C. Qin, P. Yan and M. Sui, Origins of capacity and voltage fading of $\mathrm{LiCoO}_{2}$ upon high voltage cycling, J. Mater. Chem. A, 2019, 7(36), 20824-20831.

15 S. Kalluri, M. Yoon, M. Jo, S. Park, S. Myeong, J. Kim, S. X. Dou, Z. Guo and J. Cho, Surface Engineering Strategies of Layered $\mathrm{LiCoO}_{2}$ Cathode Material to Realize High-Energy and High-Voltage Li-Ion Cells, Adv. Energy Mater., 2017, 7(1), 1601507.

16 Y. J. Kim, H. Kim, B. Kim, D. Ahn, J.-G. Lee, T.-J. Kim, D. Son, J. Cho, Y.-W. Kim and B. Park, Electrochemical Stability of Thin-Film $\mathrm{LiCoO}_{2}$ Cathodes by AluminumOxide Coating, Chem. Mater., 2003, 15(7), 1505-1511.

17 Y. Zhao, J. Li and J. R. Dahn, Interdiffusion of Cations from Metal Oxide Surface Coatings into $\mathrm{LiCoO}_{2}$ During Sintering, Chem. Mater., 2017, 29(12), 5239-5248.

18 A. Yano, M. Shikano, A. Ueda, H. Sakaebe and Z. Ogumi, $\mathrm{LiCoO}_{2}$ Degradation Behavior in the High-Voltage Phase Transition Region and Improved Reversibility with Surface Coating, J. Electrochem. Soc., 2017, 164(1), A6116A6122.

19 B. Shen, Q. Liu, L. Wang, G. Yin, P. Zuo, Y. Ma, X. Cheng, C. Du and Y. Gao, Mixed lithium ion and electron conducting $\mathrm{LiAlPO}_{3.93} \mathrm{~F}_{1.07}$-coated $\mathrm{LiCoO}_{2}$ cathode with improved electrochemical performance, Electrochem. Commun., 2017, 83, 106-109.

20 M. Kato, T. Hayashi, G. Hasegawa, X. Lu, T. Miyazaki, Y. Matsuda, N. Kuwata, K. Kurihara and J. Kawamura, Electrochemical properties of $\mathrm{LiCoO}_{2}$ thin film surface modified by lithium tantalate and lithium niobate coatings, Solid State Ionics, 2017, 308, 54-60.

21 F. Zhao, Y. Tang, J. Wang, J. Tian, H. Ge and B. Wang, Vapor-assisted synthesis of $\mathrm{Al}_{2} \mathrm{O}_{3}$-coated $\mathrm{LiCoO}_{2}$ for highvoltage lithium ion batteries, Electrochim. Acta, 2015, 174, 384-390.

22 J. S. Park, A. U. Mane, J. W. Elam and J. R. Croy, Atomic Layer Deposition of Al-W-Fluoride on $\mathrm{LiCoO}_{2}$ Cathodes: Comparison of Particle- and Electrode-Level Coatings, ACS Omega, 2017, 2(7), 3724-3729.

23 Y. Zhou, Y. Lee, H. Sun, J. M. Wallas, S. M. George and M. Xie, Coating Solution for High-Voltage Cathode: $\mathrm{AlF}_{3}$ Atomic Layer Deposition for Freestanding $\mathrm{LiCoO}_{2}$ Electrodes with High Energy Density and Excellent Flexibility, ACS Appl. Mater. Interfaces, 2017, 9(11), 96149619.

24 J.-G. Lee, B. Kim, J. Cho, Y.-W. Kim and B. Park, Effect of $\mathrm{AlPO}_{4}$-Nanoparticle Coating Concentration on High-
Cutoff-Voltage Electrochemical Performances in $\mathrm{LiCoO}_{2}, \mathrm{~J}$. Electrochem. Soc., 2004, 151(6), A801-A805.

25 X. Dai, A. Zhou, J. Xu, B. Yang, L. Wang and J. Li, Superior electrochemical performance of $\mathrm{LiCoO}_{2}$ electrodes enabled by conductive $\mathrm{Al}_{2} \mathrm{O} 3$-doped $\mathrm{ZnO}$ coating via magnetron sputtering, J. Power Sources, 2015, 298, 114-122.

26 H.-W. Ha, N. J. Yun, M. H. Kim, M. H. Woo and K. Kim, Enhanced electrochemical and thermal stability of surface-modified $\mathrm{LiCoO}_{2}$ cathode by $\mathrm{CeO}_{2}$ coating, Electrochim. Acta, 2006, 51(16), 3297-3302.

27 C. S. Yoon, D.-W. Jun, S.-T. Myung and Y.-K. Sun, Structural stability of $\mathrm{LiNiO}_{2}$ cycled above 4.2 V, ACS Energy Lett., 2017, 2(5), 1150-1155.

28 J. B. Goodenough, D. G. Wickham and W. J. Croft, Some magnetic and crystallographic properties of the system $\mathrm{Li}^{+}{ }_{x} \mathrm{Ni}^{++}{ }_{1-2 \mathrm{x}} \mathrm{Ni}^{+++}{ }_{\mathrm{x}} \mathrm{O}$, J. Phys. Chem. Solids, 1958, 5(1), 107116.

29 L. D. Dyer, B. S. Borie and G. P. Smith, Alkali Metal-Nickel Oxides of the Type $\mathrm{MNiO}_{2}$, J. Am. Chem. Soc., 1954, 76(6), 1499-1503.

30 T. Ohzuku, A. Ueda and M. Nagayama, Electrochemistry and Structural Chemistry of $\mathrm{LiNiO}_{2}(\mathrm{R} \overline{3} \mathrm{~m})$ for 4 Volt Secondary Lithium Cells, J. Electrochem. Soc., 1993, 140(7), 1862-1870.

31 W. Li, J. N. Reimers and J. R. Dahn, In situ x-ray diffraction and electrochemical studies of $\mathrm{Li}_{1-x} \mathrm{NiO}_{2}$, Solid State Ionics, 1993, 67(1), 123-130.

32 K.-K. Lee, W.-S. Yoon, K.-B. Kim, K.-Y. Lee and S.-T. Hong, Thermal behavior and the decomposition mechanism of electrochemically delithiated $\mathrm{Li}_{1-x} \mathrm{NiO}_{2}, J$. Power Sources, 2001, 97-98, 321-325.

33 H. Arai, S. Okada, Y. Sakurai and J.-i. Yamaki, Thermal behavior of $\mathrm{Li}_{1-y} \mathrm{NiO}_{2}$ and the decomposition mechanism, Solid State Ionics, 1998, 109(3), 295-302.

34 L. de Biasi, A. Schiele, M. Roca-Ayats, G. Garcia, T. Brezesinski, P. Hartmann and J. Janek, Phase Transformation Behavior and Stability of $\mathrm{LiNiO}_{2}$ Cathode Material for Li-Ion Batteries from In Situ Pressure and Gas Analysis and Operando X-Ray Diffraction, ChemSusChem, 2019, 12, 2240-2250.

35 J. R. Dahn, E. W. Fuller, M. Obrovac and U. von Sacken, Thermal stability of $\mathrm{Li}_{\mathrm{x}} \mathrm{CoO}_{2}, \mathrm{Li}_{\mathrm{x}} \mathrm{NiO}_{2}$ and $\lambda-\mathrm{MnO}_{2}$ and consequences for the safety of Li-ion cells, Solid State Ionics, 1994, 69(3), 265-270.

36 J. Cho, T.-J. Kim, Y. J. Kim and B. Park, High-performance $\mathrm{ZrO}_{2}$-coated $\mathrm{LiNiO}_{2}$ cathode material, Electrochem. SolidState Lett., 2001, 4(10), A159-A161.

37 P. Mohan and G. P. Kalaignan, Electrochemical behaviour of surface modified $\mathrm{SiO}_{2}$-coated $\mathrm{LiNiO}_{2}$ cathode materials for rechargeable lithium-ion batteries, J. Nanosci. Nanotechnol., 2013, 13(4), 2765-2770.

38 S.-W. Zhong, Y.-J. Zhao, L. Fang, L. Yan, H. Yang, P.-Z. Li, M. Jia and Q.-G. Liu, Characteristics and electrochemical performance of cathode material Co-coated $\mathrm{LiNiO}_{2}$ for Liion batteries, Trans. Nonferrous Metals Soc. China, 2006, 16(1), 137-141. 
39 X.-r. Deng, G.-r. Hu, K. Du, Z.-d. Peng, X.-G. Gao and Y.-N. Yang, Synthesis and electrochemical properties of Co, Mn-coated $\mathrm{LiNiO}_{2}$ lithium-ion battery cathode materials, Mater. Chem. Phys., 2008, 109(2-3), 469-474.

40 C. M. Julien, A. Amdouni, S. Castro-Garcia, M. Selmane and S. Rangan, $\mathrm{LiCo}_{1-\mathrm{y}} \mathrm{MyO}_{2}$ positive electrodes for rechargeable lithium batteries: II. Nickel substituted materials grown by the citrate method, Materials Science and Engineering: B, 2006, 128(1), 138-150.

41 A. Rougier, I. Saadoune, P. Gravereau, P. Willmann and C. Delmasa, Effect of cobalt substitution on cationic distribution in $\mathrm{LiNi}_{1-\mathrm{y}} \mathrm{Co}_{\mathrm{y}} \mathrm{O}_{2}$ electrode materials, Solid State Ionics, 1996, 90(1), 83-90.

42 D. Caurant, N. Baffier, B. Garcia and J. P. Pereira-Ramos, Synthesis by a soft chemistry route and characterization of $\mathrm{LiNi}_{\mathrm{x}} \mathrm{Co}_{1-\mathrm{x}} \mathrm{O}_{2}(0 \leq \mathrm{x} \leq 1)$ cathode materials, Solid State Ionics, 1996, 91(1), 45-54.

43 J. Cho, H. Jung, Y. Park, G. Kim and H. S. Lim, Electrochemical Properties and Thermal Stability of $\mathrm{Li}$ a $\mathrm{Ni}_{1-\mathrm{x}} \mathrm{CO}_{\mathrm{x}} \mathrm{O}_{2}$ Cathode Materials, J. Electrochem. Soc., 2000, 147(1), 15-20.

44 Q. Xie, W. Li and A. Manthiram, A Mg-doped High-nickel Layered Oxide Cathode Enabling Safer, High-energydensity Li-ion Batteries, Chem. Mater., 2019, 31(3), 938-946.

45 H. Li, P. Zhou, F. Liu, H. Li, F. Cheng and J. Chen, Stabilizing nickel-rich layered oxide cathodes by magnesium doping for rechargeable lithium-ion batteries, Chem. Sci., 2019, 10(5), 1374-1379.

46 C. S. Yoon, H.-H. Ryu, G.-T. Park, J.-H. Kim, K.-H. Kim and Y.-K. Sun, Extracting maximum capacity from Ni-rich $\mathrm{Li}$ $\left[\mathrm{Ni}_{0.95} \mathrm{Co}_{0.025} \mathrm{Mn}_{0.025}\right] \mathrm{O}_{2}$ cathodes for high-energy-density lithium-ion batteries, J. Mater. Chem. A, 2018, 6(9), 41264132.

47 K.-S. Lee, S.-T. Myung, D.-W. Kim and Y.-K. Sun, $\mathrm{AlF}_{3}$-coated $\mathrm{LiCoO}_{2}$ and $\mathrm{Li}\left[\mathrm{Ni}_{1 / 3} \mathrm{Co}_{1 / 3} \mathrm{Mn}_{1 / 3}\right] \mathrm{O}_{2}$ blend composite cathode for lithium ion batteries, J. Power Sources, 2011, 196(16), 6974-6977.

48 M.-H. Liu, C.-W. Jen, J.-M. Chen and S.-C. Liao, Improved Electrochemical Performance of Ni-rich Cathode Materials via Al Gradient Doping, Int. J. Electrochem. Sci., 2018, 13(5), 4350-4366.

49 H.-H. Sun and A. Manthiram, Impact of microcrack generation and surface degradation on a nickel-rich layered $\mathrm{Li}\left[\mathrm{Ni}_{0.9} \mathrm{Co}_{0.05} \mathrm{Mn}_{0.05}\right] \mathrm{O}_{2}$ cathode for lithium-ion batteries, Chem. Mater., 2017, 29(19), 8486-8493.

50 J. M. Paulsen, C. L. Thomas and J. R. Dahn, Layered Li-Mn-Oxide with the $\mathrm{O}_{2}$ Structure: A Cathode Material for Li-Ion Cells which does not Convert to Spinel, J. Electrochem. Soc., 1999, 146(10), 3560-3565.

51 A. R. Armstrong and P. G. Bruce, Synthesis of layered $\mathrm{LiMnO}_{2}$ as an electrode for rechargeable lithium batteries, Nature, 1996, 381, 499.

52 G. Ceder and S. K. Mishra, The Stability of Orthorhombic and Monoclinic-Layered $\mathrm{LiMnO}_{2}$, Electrochem. Solid-State Lett., 1999, 2(11), 550-552.

53 A. R. Armstrong, N. Dupre, A. J. Paterson, C. P. Grey and P. G. Bruce, Combined Neutron Diffraction, NMR, and
Electrochemical Investigation of the Layered-to-Spinel Transformation in $\mathrm{LiMnO}_{2}$, Chem. Mater., 2004, 16(16), 3106-3118.

54 B. Ammundsen, J. Desilvestro, T. Groutso, D. Hassell, J. B. Metson, E. Regan, R. Steiner and P. J. Pickering, Formation and Structural Properties of Layered $\mathrm{LiMnO}_{2}$ Cathode Materials, J. Electrochem. Soc., 2000, 147(11), 4078-4082.

55 R. Saroha, A. Gupta and A. K. Panwar, Electrochemical performances of Li-rich layered-layered $\mathrm{Li}_{2} \mathrm{MnO}_{3}-\mathrm{LiMnO}_{2}$ solid solutions as cathode material for lithium-ion batteries, J. Alloys Compd., 2017, 696, 580-589.

56 W.-S. Yoon, M. Balasubramanian, X.-Q. Yang, Z. Fu, D. A. Fischer and J. McBreen, Soft X-Ray Absorption Spectroscopic Study of a $\mathrm{LiNi}_{0.5} \mathrm{Mn}_{0.5} \mathrm{O}_{2}$ Cathode during Charge, J. Electrochem. Soc., 2004, 151(2), A246-A251.

57 A. Deb, U. Bergmann, S. P. Cramer and E. J. Cairns, Local structure of $\mathrm{LiNi}_{0.5} \mathrm{Mn}_{0.5} \mathrm{O}_{2}$ cathode material probed by in situ x-ray absorption spectroscopy, J. Appl. Phys., 2006, 99(6), 063701.

58 W.-S. Yoon, S. Iannopollo, C. P. Grey, D. Carlier, J. Gorman, J. Reed and G. Ceder, Local Structure and Cation Ordering in O3 Lithium Nickel Manganese Oxides with Stoichiometry $\mathrm{Li}\left[\mathrm{Ni}_{\mathrm{x}} \mathrm{Mn}_{(2-\mathrm{x}) / 3} \mathrm{Li}_{(1-2 \mathrm{x}) / 3}\right] \mathrm{O}_{2}$ : NMR Studies and First Principles Calculations, Electrochem. Solid-State Lett., 2004, 7(7), A167-A171.

59 Y. Hinuma, Y. S. Meng, K. Kang and G. Ceder, Phase Transitions in the $\mathrm{LiNi}_{0.5} \mathrm{Mn}_{0.5} \mathrm{O}_{2}$ System with Temperature, Chem. Mater., 2007, 19(7), 1790-1800.

60 H. Kobayashi, H. Sakaebe, H. Kageyama, K. Tatsumi, Y. Arachi and T. Kamiyama, Changes in the structure and physical properties of the solid solution $\mathrm{LiNi}_{1-\mathrm{x}} \mathrm{Mn}_{\mathrm{x}} \mathrm{O}_{2}$ with variation in its composition, J. Mater. Chem., 2003, 13(3), 590-595.

61 H. H. Li, N. Yabuuchi, Y. S. Meng, S. Kumar, J. Breger, C. P. Grey and Y. Shao-Horn, Changes in the Cation Ordering of Layered $\mathrm{O}_{3} \quad \mathrm{Li}_{\mathrm{x}} \mathrm{Ni}_{0.5} \mathrm{Mn}_{0.5} \mathrm{O}_{2}$ during Electrochemical Cycling to High Voltages: An Electron Diffraction Study, Chem. Mater., 2007, 19(10), 2551-2565.

62 Y. S. Meng, G. Ceder, C. P. Grey, W.-S. Yoon and Y. ShaoHorn, Understanding the Crystal Structure of Layered $\mathrm{LiNi}_{0.5} \mathrm{Mn}_{0.5} \mathrm{O}_{2}$ by Electron Diffraction and Powder Diffraction Simulation, Electrochem. Solid-State Lett., 2004, 7(6), A155-A158.

63 W.-S. Yoon, Y. Paik, X.-Q. Yang, M. Balasubramanian, J. McBreen and C. P. Grey, Investigation of the Local Structure of the $\mathrm{LiNi}_{0.5} \mathrm{Mn}_{0.5} \mathrm{O}_{2}$ Cathode Material during Electrochemical Cycling by X-Ray Absorption and NMR Spectroscopy, Electrochem. Solid-State Lett., 2002, 5(11), A263-A266.

64 A. Van der Ven and G. Ceder, Ordering in $\mathrm{Li}_{\mathrm{x}}\left(\mathrm{Ni}_{0.5} \mathrm{Mn}_{0.5}\right) \mathrm{O}_{2}$ and its relation to charge capacity and electrochemical behavior in rechargeable lithium batteries, Electrochem. Commun., 2004, 6(10), 1045-1050.

65 J. Bréger, Y. S. Meng, Y. Hinuma, S. Kumar, K. Kang, Y. Shao-Horn, G. Ceder and C. P. Grey, Effect of High Voltage on the Structure and Electrochemistry of 
$\mathrm{LiNi}_{0.5} \mathrm{Mn}_{0.5} \mathrm{O}_{2}$ : A Joint Experimental and Theoretical Study, Chem. Mater., 2006, 18(20), 4768-4781.

66 D. D. MacNeil, Z. Lu and J. R. Dahn, Structure and Electrochemistry of $\mathrm{Li}\left[\mathrm{Ni}_{\mathrm{x}} \mathrm{Co}_{1-2 \mathrm{x}} \mathrm{Mn}_{\mathrm{x}}\right] \mathrm{O}_{2} \quad(0 \leq \mathrm{x} \leq 1 / 2), \quad J$. Electrochem. Soc., 2002, 149(10), A1332-A1336.

67 Y. W. Tsai, B. J. Hwang, G. Ceder, H. S. Sheu, D. G. Liu and J. F. Lee, In-Situ X-ray Absorption Spectroscopic Study on Variation of Electronic Transitions and Local Structure of $\mathrm{LiNi}_{1 / 3} \mathrm{Co}_{1 / 3} \mathrm{Mn}_{1 / 3} \mathrm{O}_{2} \quad$ Cathode Material during Electrochemical Cycling, Chem. Mater., 2005, 17(12), 3191-3199.

68 W.-S. Yoon, M. Balasubramanian, K. Y. Chung, X.-Q. Yang, J. McBreen, C. P. Grey and D. A. Fischer, Investigation of the Charge Compensation Mechanism on the Electrochemically Li-Ion Deintercalated $\mathrm{Li}_{1-\mathrm{x}} \mathrm{Co}_{1 / 3} \mathrm{Ni}_{1 / 3} \mathrm{Mn}_{1 / 3} \mathrm{O}_{2} \quad$ Electrode System by Combination of Soft and Hard X-ray Absorption Spectroscopy, J. Am. Chem. Soc., 2005, 127(49), 17479-17487.

69 M. G. Kim, H. J. Shin, J.-H. Kim, S.-H. Park and Y.-K. Sun, XAS Investigation of Inhomogeneous Metal-Oxygen Bond Covalency in Bulk and Surface for Charge Compensation in Li-Ion Battery Cathode $\mathrm{Li}\left[\mathrm{Ni}_{1 / 3} \mathrm{Co}_{1 / 3} \mathrm{Mn}_{1 / 3}\right] \mathrm{O}_{2}$ Material, J. Electrochem. Soc., 2005, 152(7), A1320-A1328.

70 C. S. Johnson, J. S. Kim, C. Lefief, N. Li, J. T. Vaughey and M. M. Thackeray, The significance of the $\mathrm{Li}_{2} \mathrm{MnO}_{3}$ component in 'composite' $\mathrm{xLi}_{2} \mathrm{MnO}_{3} \cdot(1-\mathrm{x}) \mathrm{LiMn}_{0.5} \mathrm{Ni}_{0.5} \mathrm{O}_{2}$ electrodes, Electrochem. Commun., 2004, 6(10), 1085-1091.

71 P. Kalyani, S. Chitra, T. Mohan and S. Gopukumar, Lithium metal rechargeable cells using $\mathrm{Li}_{2} \mathrm{MnO}_{3}$ as the positive electrode, J. Power Sources, 1999, 80(1), 103-106.

72 M. M. Thackeray, Manganese oxides for lithium batteries, Prog. Solid State Chem., 1997, 25(1), 1-71.

73 S. Hy, F. Felix, J. Rick, W.-N. Su and B. J. Hwang, Direct In situ Observation of $\mathrm{Li}_{2} \mathrm{O}$ Evolution on Li-Rich HighCapacity Cathode Material, $\mathrm{Li}\left[\mathrm{Ni}_{\mathrm{x}} \mathrm{Li}_{(1-2 \mathrm{x}) / 3} \mathrm{Mn}_{(2-\mathrm{x}) / 3}\right] \mathrm{O}_{2}(0 \leq$ $\mathrm{x} \leq 0.5)$, J. Am. Chem. Soc., 2014, 136(3), 999-1007.

74 A. D. Robertson and P. G. Bruce, Mechanism of Electrochemical Activity in $\mathrm{Li}_{2} \mathrm{MnO}_{3}$, Chem. Mater., 2003, 15(10), 1984-1992.

$75 \mathrm{H}$. Chen and M. S. Islam, Lithium Extraction Mechanism in Li-Rich $\mathrm{Li}_{2} \mathrm{MnO}_{3}$ Involving Oxygen Hole Formation and Dimerization, Chem. Mater., 2016, 28(18), 6656-6663.

76 J. Rana, M. Stan, R. Kloepsch, J. Li, G. Schumacher, E. Welter, I. Zizak, J. Banhart and M. Winter, Structural Changes in $\mathrm{Li}_{2} \mathrm{MnO}_{3}$ Cathode Material for Li-Ion Batteries, Adv. Energy Mater., 2014, 4(5), 1300998.

77 M. Gu, A. Genc, I. Belharouak, D. Wang, K. Amine, S. Thevuthasan, D. R. Baer, J.-G. Zhang, N. D. Browning, J. Liu and C. Wang, Nanoscale Phase Separation, Cation Ordering, and Surface Chemistry in Pristine $\mathrm{Li}_{1.2} \mathrm{Ni}_{0.2} \mathrm{Mn}_{0.6} \mathrm{O}_{2}$ for Li-Ion Batteries, Chem. Mater., 2013, 25(11), 2319-2326.

78 Z. Lu, D. D. MacNeil and J. R. Dahn, Layered Cathode Materials $\mathrm{Li}\left[\mathrm{Ni}_{\mathrm{x}} \mathrm{Li}_{(1 / 3-2 \mathrm{x} / 3)} \mathrm{Mn}_{(2 / 3-\mathrm{x} / 3)}\right] \mathrm{O}_{2}$ for Lithium-Ion Batteries, Electrochem. Solid-State Lett., 2001, 4(11), A191A194.
79 Z. Lu, Z. Chen and J. R. Dahn, Lack of Cation Clustering in Li $\left[\mathrm{Ni}_{\mathrm{x}} \mathrm{Li}_{1 / 3-2 \mathrm{x} / 3} \mathrm{Mn}_{2 / 3-\mathrm{x} / 3}\right] \mathrm{O}_{2}(0<\mathrm{x} \leq 1 / 2)$ and $\mathrm{Li}\left[\mathrm{Cr}_{\mathrm{x}} \mathrm{Li}_{(1-\mathrm{x}) / 3} \mathrm{Mn}_{(2-2 \mathrm{x}) / 3}\right]$ $\mathrm{O}_{2}(0<\mathrm{x}<1)$, Chem. Mater., 2003, 15(16), 3214-3220.

80 R. Wang, X. He, L. He, F. Wang, R. Xiao, L. Gu, H. Li and L. Chen, Atomic Structure of $\mathrm{Li}_{2} \mathrm{MnO}_{3}$ after Partial Delithiation and Re-Lithiation, Adv. Energy Mater., 2013, 3(10), 1358-1367.

81 S. Guo, H. Yu, P. Liu, X. Liu, D. Li, M. Chen, M. Ishida and H. Zhou, Surface coating of lithium-manganese-rich layered oxides with delaminated $\mathrm{MnO}_{2}$ nanosheets as cathode materials for Li-ion batteries, J. Mater. Chem. A, 2014, 2(12), 4422-4428.

82 M. N. Ates, Q. Jia, A. Shah, A. Busnaina, S. Mukerjee and K. M. Abraham, Mitigation of Layered to Spinel Conversion of a Li-Rich Layered Metal Oxide Cathode Material for Li-Ion Batteries, J. Electrochem. Soc., 2014, 161(3), A290-A301.

83 F. Wu, N. Li, Y. Su, H. Shou, L. Bao, W. Yang, L. Zhang, R. An and S. Chen, Spinel/Layered Heterostructured Cathode Material for High-Capacity and High-Rate Li-Ion Batteries, Adv. Mater., 2013, 25(27), 3722-3726.

84 D. Mohanty, J. Li, D. P. Abraham, A. Huq, E. A. Payzant, D. L. Wood and C. Daniel, Unraveling the Voltage-Fade Mechanism in High-Energy-Density Lithium-Ion Batteries: Origin of the Tetrahedral Cations for Spinel Conversion, Chem. Mater., 2014, 26(21), 6272-6280.

85 Y. Xu, E. Hu, F. Yang, J. Corbett, Z. Sun, Y. Lyu, X. Yu, Y. Liu, X.-Q. Yang and H. Li, Structural integrity-Searching the key factor to suppress the voltage fade of Li-rich layered cathode materials through 3D X-ray imaging and spectroscopy techniques, Nano Energy, 2016, 28, 164-171.

86 Y. Xiang, Z. Sun, J. Li, X. Wu, Z. Liu, L. Xiong, Z. He, B. Long, C. Yang and $\mathrm{Z}$. Yin, Improved electrochemical performance of $\mathrm{Li}_{1.2} \mathrm{Ni}_{0.2} \mathrm{Mn}_{0.6} \mathrm{O}_{2}$ cathode material for lithium ion batteries synthesized by the polyvinyl alcohol assisted solgel method, Ceram. Int., 2017, 43(2), 2320-2324.

87 Y.-X. Yin, S. Xin and Y.-G. Guo, Nanoparticles Engineering for Lithium-Ion Batteries, Part. Part. Syst. Charact., 2013, 30(9), 737-753.

88 L. Chen, Y. Su, S. Chen, N. Li, L. Bao, W. Li, Z. Wang, M. Wang and F. Wu, Hierarchical $\mathrm{Li}_{1.2} \mathrm{Ni}_{0.2} \mathrm{Mn}_{0.6} \mathrm{O}_{2}$ Nanoplates with Exposed $\{010\}$ Planes as HighPerformance Cathode Material for Lithium-Ion Batteries, Adv. Mater., 2014, 26(39), 6756-6760.

89 C. Yang, Y. Deng, M. Gao, X. Yang, X. Qin and G. Chen, High-rate and long-life performance of a truncated spinel cathode material with off-stoichiometric composition at elevated temperature, Electrochim. Acta, 2017, 225, 198-206.

90 K. R. Ragavendran, H. Xia, G. Yang, D. Vasudevan, B. Emmanuel, D. Sherwood and A. K. Arof, On the theory of high rate capability of $\mathrm{LiMn}_{2} \mathrm{O}_{4}$ with some preferred orientations: insights from the crystal shape algorithm, Phys. Chem. Chem. Phys., 2014, 16(6), 2553-2560.

91 C. M. Sim, S. H. Choi and Y. C. Kang, Superior electrochemical properties of $\mathrm{LiMn}_{2} \mathrm{O}_{4}$ yolk-shell powders prepared by a simple spray pyrolysis process, Chem. Commun., 2013, 49(53), 5978-5980. 
92 M. M. Thackeray, Y. Shao-Horn, A. J. Kahaian, K. D. Kepler, E. Skinner, J. T. Vaughey and S. A. Hackney, Structural Fatigue in Spinel Electrodes in High Voltage (4 V) Li/ $\mathrm{Li}_{\mathrm{x}} \mathrm{Mn}_{2} \mathrm{O}_{4}$ Cells, Electrochem. Solid-State Lett., 1998, 1(1), 7-9.

$93 \mathrm{~J}$. Choa and M. M. Thackeray, Structural Changes of $\mathrm{LiMn}_{2} \mathrm{O}_{4}$ Spinel Electrodes during Electrochemical Cycling, J. Electrochem. Soc., 1999, 146(10), 3577-3581.

94 M. Hirayama, H. Ido, K. Kim, W. Cho, K. Tamura, J. i. Mizuki and R. Kanno, Dynamic Structural Changes at $\mathrm{LiMn}_{2} \mathrm{O}_{4} /$ Electrolyte Interface during Lithium Battery Reaction, J. Am. Chem. Soc., 2010, 132(43), 15268-15276.

95 S. Lee, Y. Cho, H.-K. Song, K. T. Lee and J. Cho, CarbonCoated Single-Crystal $\mathrm{LiMn}_{2} \mathrm{O}_{4}$ Nanoparticle Clusters as Cathode Material for High-Energy and High-Power Lithium-Ion Batteries, Angew. Chem., Int. Ed., 2012, 51(35), 8748-8752.

96 J. Cho, G. B. Kim, H. S. Lim, C. S. Kim and S. I. Yoo, Improvement of Structural Stability of $\mathrm{LiMn}_{2} \mathrm{O}_{4}$ Cathode Material on $55^{\circ} \mathrm{C}$ Cycling by Sol-Gel Coating of $\mathrm{LiCoO}_{2}$, Electrochem. Solid-State Lett., 1999, 2(12), 607-609.

97 C. Zhang, X. Liu, Q. Su, J. Wu, T. Huang and A. Yu, Enhancing Electrochemical Performance of $\mathrm{LiMn}_{2} \mathrm{O}_{4}$ Cathode Material at Elevated Temperature by Uniform Nanosized $\mathrm{TiO}_{2}$ Coating, ACS Sustainable Chem. Eng., 2017, 5(1), 640-647.

98 Y.-K. Sun, K.-J. Hong and J. Prakash, The Effect of ZnO Coating on Electrochemical Cycling Behavior of Spinel $\mathrm{LiMn}_{2} \mathrm{O}_{4}$ Cathode Materials at Elevated Temperature, $J$. Electrochem. Soc., 2003, 150(7), A970-A972.

99 D.-Q. Liu, X.-Q. Liu and Z.-Z. He, The elevated temperature performance of $\mathrm{LiMn}_{2} \mathrm{O}_{4}$ coated with $\mathrm{Li}_{4} \mathrm{Ti}_{5} \mathrm{O}_{12}$ for lithium ion battery, Mater. Chem. Phys., 2007, 105(2), 362-366.

100 L. Xiao, Y. Zhao, Y. Yang, Y. Cao, X. Ai and H. Yang, Enhanced electrochemical stability of Al-doped $\mathrm{LiMn}_{2} \mathrm{O}_{4}$ synthesized by a polymer-pyrolysis method, Electrochim. Acta, 2008, 54(2), 545-550.

101 J. H. Lee, J. K. Hong, D. H. Jang, Y. K. Sun and S. M. Oh, Degradation mechanisms in doped spinels of $\mathrm{LiM}_{0.05} \mathrm{Mn}_{1.95} \mathrm{O}_{4} \quad(\mathrm{M}=\mathrm{Li}, \quad \mathrm{B}, \quad \mathrm{Al}, \mathrm{Co}$, and $\mathrm{Ni})$ for $\mathrm{Li}$ secondary batteries, J. Power Sources, 2000, 89(1), 7-14.

102 S.-J. Bao, Y.-Y. Liang, W.-J. Zhou, B.-L. He and H.-L. Li, Enhancement of the electrochemical properties of LiMn $_{2} \mathrm{O}_{4}$ through $\mathrm{Al}^{3+}$ and $\mathrm{F}^{-}$co-substitution, J. Colloid Interface Sci., 2005, 291(2), 433-437.

103 G. Amatucci, A. Du Pasquier, A. Blyr, T. Zheng and J. M. Tarascon, The elevated temperature performance of the $\mathrm{LiMn}_{2} \mathrm{O}_{4} / \mathrm{C}$ system: failure and solutions, Electrochim. Acta, 1999, 45(1), 255-271.

104 G. Q. Liu, L. Wen and Y. M. Liu, Spinel $\mathrm{LiNi}_{0.5} \mathrm{Mn}_{1.5} \mathrm{O}_{4}$ and its derivatives as cathodes for high-voltage Li-ion batteries, J. Solid State Electrochem., 2010, 14(12), 2191-2202.

105 J. H. Kim, S. T. Myung, C. S. Yoon, S. G. Kang and Y. K. Sun, Comparative Study of $\mathrm{LiNi}_{0.5} \mathrm{Mn}_{1.5} \mathrm{O}_{4-\delta}$ and $\mathrm{LiNi}_{0.5} \mathrm{Mn}_{1.5} \mathrm{O}_{4}$ Cathodes Having Two Crystallographic Structures: Fd $\overline{3} \mathrm{~m}$ and $\mathrm{P}_{3} 32$, Chem. Mater., 2004, 16(5), 906-914.
106 R. Santhanam and B. Rambabu, Research progress in high voltage spinel $\mathrm{LiNi}_{0.5} \mathrm{Mn}_{1.5} \mathrm{O}_{4}$ material, J. Power Sources, 2010, 195(17), 5442-5451.

107 G. Rousse, J. Rodriguez-Carvajal, S. Patoux and C. Masquelier, Magnetic Structures of the Triphylite $\mathrm{LiFePO}_{4}$ and of its Delithiated Form $\mathrm{FePO}_{4}$, Chem. Mater., 2003, 15(21), 4082-4090.

108 J. Hong, F. Wang, X. Wang and J. Graetz, $\mathrm{LiFe}_{\mathrm{x}} \mathrm{Mn}_{1-\mathrm{x}} \mathrm{PO}_{4}$ : a cathode for lithium-ion batteries, J. Power Sources, 2011, 196(7), 3659-3663.

109 Y.-M. Kang, Y.-I. Kim, M.-W. Oh, R.-Z. Yin, Y. Lee, D.-W. Han, H.-S. Kwon, J. H. Kim and G. Ramanath, Structurally stabilized olivine lithium phosphate cathodes with enhanced electrochemical properties through $\mathrm{Fe}$ doping, Energy Environ. Sci., 2011, 4(12), 4978-4983.

110 R. Qing, M.-C. Yang, Y. S. Meng and W. Sigmund, Synthesis of $\mathrm{LiNi}_{\mathrm{x}} \mathrm{Fe}_{1-\mathrm{x}} \mathrm{PO}_{4}$ solid solution as cathode materials for lithium ion batteries, Electrochim. Acta, 2013, 108, 827-832.

111 A. K. Padhi, K. S. Nanjundaswamy and J. B. Goodenough, Phospho-olivines as Positive-Electrode Materials for Rechargeable Lithium Batteries, J. Electrochem. Soc., 1997, 144(4), 1188-1194.

112 V. Srinivasan and J. Newman, Discharge Model for the Lithium Iron-Phosphate Electrode, J. Electrochem. Soc., 2004, 151(10), A1517-A1529.

113 S. Sun, T. Guan, B. Shen, K. Leng, Y. Gao, X. Cheng and G. Yin, Changes of degradation mechanisms of $\mathrm{LiFePO}_{4} /$ graphite batteries cycled at different ambient temperatures, Electrochim. Acta, 2017, 237, 248-258.

114 Y. Zhu, J. W. Wang, Y. Liu, X. Liu, A. Kushima, Y. Liu, Y. Xu, S. X. Mao, J. Li and C. Wang, In situ atomic-scale imaging of phase boundary migration in $\mathrm{FePO}_{4}$ microparticles during electrochemical lithiation, Adv. Mater., 2013, 25(38), 54615466.

115 D. Li, D. L. Danilov, B. Zwikirsch, M. Fichtner, Y. Yang, R.-A. Eichel and P. H. Notten, Modeling the degradation mechanisms of $\mathrm{C}_{6} / \mathrm{LiFePO}_{4}$ batteries, J. Power Sources, 2018, 375, 106-117.

116 M. Herstedt, M. Stjerndahl, A. Nytén, T. Gustafsson, H. Rensmo, H. Siegbahn, N. Ravet, M. Armand, J. O. Thomas and K. Edström, Surface Chemistry of Carbon-Treated $\mathrm{LiFePO}_{4}$ Particles for Li-Ion Battery Cathodes Studied by PES, Electrochem. Solid-State Lett., 2003, 6(9), A202-A206.

117 H. Huang, S.-C. Yin and L. F. Nazar, Approaching Theoretical Capacity of $\mathrm{LiFePO}_{4}$ at Room Temperature at High Rates, Electrochem. Solid-State Lett., 2001, 4(10), A170-A172.

118 C. M. Julien, A. Mauger, A. Ait-Salah, M. Massot, F. Gendron and K. Zaghib, Nanoscopic scale studies of $\mathrm{LiFePO}_{4}$ as cathode material in lithium-ion batteries for $\mathrm{HEV}$ application, Ionics, 2007, 13(6), 395-411.

119 C. Delacourt, P. Poizot, S. Levasseur and C. Masquelier, Size Effects on Carbon-Free $\mathrm{LiFePO}_{4}$ Powders: The Key to Superior Energy Density, Electrochem. Solid-State Lett., 2006, 9(7), A352-A355. 
120 S.-Y. Chung, J. T. Bloking and Y.-M. Chiang, Electronically conductive phospho-olivines as lithium storage electrodes, Nat. Mater., 2002, 1, 123.

121 P. S. Herle, B. Ellis, N. Coombs and L. F. Nazar, Nanonetwork electronic conduction in iron and nickel olivine phosphates, Nat. Mater., 2004, 3, 147.

122 Y. Li, Y. Zhang, J. Ma, L. Yang, X. Li, E. Zhao, S. Fan, G. Xu, S. Yang and C. Yang, Synthesis of $\mathrm{LiFePO}_{4}$ Nanocomposite with Surface Conductive Phase by Zr Doping with Li Excess for Fast Discharging, J. Electrochem. Soc., 2019, 166(2), A410-A415.

123 C. M. Julien, K. Zaghib, A. Mauger and H. Groult, Enhanced electrochemical properties of $\mathrm{LiFePO}_{4}$ as positive electrode of Li-ion batteries for HEV application, Adv. Chem. Eng. Sci., 2012, 2(03), 321.

124 V. Aravindan, J. Gnanaraj, Y.-S. Lee and S. Madhavi, $\mathrm{LiMnPO}_{4}$ - a next generation cathode material for lithium-ion batteries, J. Mater. Chem. A, 2013, 1(11), 35183539.

125 H. Wang, Y. I. Jang and Y. M. Chiang, Origin of Cycling Stability in Monoclinic- and Orthorhombic-Phase Lithium Manganese Oxide Cathodes, Electrochem. Solid-State Lett., 1999, 2(10), 490-493.

126 T. Shiratsuchi, S. Okada, T. Doi and J.-i. Yamaki, Cathodic performance of $\mathrm{LiMn}_{1-\mathrm{x}} \mathrm{M}_{\mathrm{x}} \mathrm{PO}_{4} \quad(\mathrm{M}=\mathrm{Ti}, \mathrm{Mg}$ and $\mathrm{Zr})$ annealed in an inert atmosphere, Electrochim. Acta, 2009, 54(11), 3145-3151.

127 D. Wang, C. Ouyang, T. Drézen, I. Exnar, A. Kay, N.-H. Kwon, P. Gouerec, J. H. Miners, M. Wang and M. Grätzel, Improving the Electrochemical Activity of $\mathrm{LiMnPO}_{4}$ via Mn-Site Substitution, J. Electrochem. Soc., 2010, 157(2), A225-A229.

128 C. Hu, H. Yi, H. Fang, B. Yang, Y. Yao, W. Ma and Y. Dai, Improving the electrochemical activity of $\mathrm{LiMnPO}_{4}$ via Mn-site co-substitution with $\mathrm{Fe}$ and $\mathrm{Mg}$, Electrochem. Commun., 2010, 12(12), 1784-1787.

129 S. K. Martha, J. Grinblat, O. Haik, E. Zinigrad, T. Drezen, J. H. Miners, I. Exnar, A. Kay, B. Markovsky and D. Aurbach, $\mathrm{LiMn}_{0.8} \mathrm{Fe}_{0.2} \mathrm{PO}_{4}$ : An Advanced Cathode Material for Rechargeable Lithium Batteries, Angew. Chem., Int. Ed., 2009, 48(45), 8559-8563.

130 S.-M. Oh, H.-G. Jung, C. S. Yoon, S.-T. Myung, Z. Chen, K. Amine and Y.-K. Sun, Enhanced electrochemical performance of carbon- $\mathrm{LiMn}_{1-\mathrm{x}} \mathrm{Fe}_{\mathrm{x}} \mathrm{PO}_{4}$ nanocomposite cathode for lithium-ion batteries, J. Power Sources, 2011, 196(16), 6924-6928.

131 I. Seo, B. Senthilkumar, K.-H. Kim, J.-K. Kim, Y. Kim and J.-H. Ahn, Atomic structural and electrochemical impact of Fe substitution on nano porous $\mathrm{LiMnPO}_{4}, J$. Power Sources, 2016, 320, 59-67.

132 H. Fang, E. Dai, B. Yang, Y. Yao and W. Ma, $\mathrm{LiMn}_{0.8} \mathrm{Fe}_{0.19} \mathrm{Mg}_{0.01} \mathrm{PO}_{4} / \mathrm{C}$ as a high performance cathode material for lithium ion batteries, J. Power Sources, 2012, 204, 193-196.

133 S. Liu, H. Fang, E. Dai, B. Yang, Y. Yao, W. Ma and Y. Dai, Effect of carbon content on properties of
$\mathrm{LiMn}_{0.8} \mathrm{Fe}_{0.19} \mathrm{Mg}_{0.01} \mathrm{PO}_{4} / \mathrm{C}$ composite cathode for lithium ion batteries, Electrochim. Acta, 2014, 116, 97-102.

134 X. Wu, M. Meledina, H. Tempel, H. Kungl, J. Mayer and R.-A. Eichel, Morphology-controllable synthesis of $\mathrm{LiCoPO}_{4}$ and its influence on electrochemical performance for high-voltage lithium ion batteries, $J$. Power Sources, 2020, 450, 227726.

$135 \mathrm{~J}$. Wolfenstine and J. Allen, $\mathrm{LiNiPO}_{4}-\mathrm{LiCoPO}_{4}$ solid solutions as cathodes, J. Power Sources, 2004, 136(1), 150153.

136 H. N. Girish and G. Q. Shao, Advances in high-capacity $\mathrm{Li}_{2} \mathrm{MSiO}_{4}(\mathrm{M}[$ space $]=\mathrm{Mn}, \mathrm{Fe}, \mathrm{Co}, \mathrm{Ni}, \ldots)$ cathode materials for lithium-ion batteries, $R S C A d v ., 2015,5(119)$, 98666-98686.

137 A. Nytén, A. Abouimrane, M. Armand, T. Gustafsson and J. O. Thomas, Electrochemical performance of $\mathrm{Li}_{2} \mathrm{FeSiO}_{4}$ as a new Li-battery cathode material, Electrochem. Commun., 2005, 7(2), 156-160.

138 A. Nyten, S. Kamali, L. Haggstrom, T. Gustafsson and J. O. Thomas, The lithium extraction/insertion mechanism in $\mathrm{Li}_{2} \mathrm{FeSiO}_{4}$, J. Mater. Chem., 2006, 16(23), 2266-2272.

139 S.-i. Nishimura, S. Hayase, R. Kanno, M. Yashima, N. Nakayama and A. Yamada, Structure of $\mathrm{Li}_{2} \mathrm{FeSiO}_{4}, J$. Am. Chem. Soc., 2008, 130(40), 13212-13213.

140 C. Sirisopanaporn, A. Boulineau, D. Hanzel, R. Dominko, B. Budic, A. R. Armstrong, P. G. Bruce and C. Masquelier, Crystal Structure of a New Polymorph of $\mathrm{Li}_{2} \mathrm{FeSiO}_{4}$, Inorg. Chem., 2010, 49(16), 7446-7451.

141 C. Sirisopanaporn, C. Masquelier, P. G. Bruce, A. R. Armstrong and R. Dominko, Dependence of $\mathrm{Li}_{2} \mathrm{FeSiO}_{4}$ Electrochemistry on Structure, J. Am. Chem. Soc., 2011, 133(5), 1263-1265.

142 M. E. Arroyo-deDompablo, R. Dominko, J. M. GallardoAmores, L. Dupont, G. Mali, H. Ehrenberg, J. Jamnik and E. Morán, On the Energetic Stability and Electrochemistry of $\mathrm{Li}_{2} \mathrm{MnSiO}_{4}$ Polymorphs, Chem. Mater., 2008, 20(17), 5574-5584.

143 R. Dominko, $\mathrm{Li}_{2} \mathrm{MSiO}_{4}(\mathrm{M}=\mathrm{Fe}$ and/or $\mathrm{Mn})$ cathode materials, J. Power Sources, 2008, 184(2), 462-468.

144 D. Santamaría-Pérez, U. Amador, J. Tortajada, R. Dominko and M. E. Arroyo-de Dompablo, High-Pressure Investigation of $\mathrm{Li}_{2} \mathrm{MnSiO}_{4}$ and $\mathrm{Li}_{2} \mathrm{CoSiO}_{4}$ Electrode Materials for Lithium-Ion Batteries, Inorg. Chem., 2012, 51(10), 5779-5786.

145 M. E. Arroyo y de Dompablo, J. M. Gallardo-Amores, J. García-Martínez, E. Morán, J. M. Tarascon and M. Armand, Is it possible to prepare olivine-type $\mathrm{LiFeSiO}_{4}$ ?: a joint computational and experimental investigation, Solid State Ionics, 2008, 179(27), 1758-1762.

146 P. Ghosh, S. Mahanty and R. N. Basu, Improved Electrochemical Performance of $\mathrm{Li}_{2} \mathrm{MnSiO}_{4} / \mathrm{C}$ Composite Synthesized by Combustion Technique, J. Electrochem. Soc., 2009, 156(8), A677-A681.

147 Y. Feng, R. Ji, Z. Ding, D. Zhang, C. Liang, L. Chen, D. G. Ivey and W. Wei, Understanding the Improved 
Kinetics and Cyclability of a $\mathrm{Li}_{2} \mathrm{MnSiO}_{4}$ Cathode with Calcium Substitution, Inorg. Chem., 2018, 57(6), 3223-3231.

148 H.-M. Cheng, S.-X. Zhao, X. Wu, J.-W. Zhao, L. Wei and C.-W. Nan, Synthesis and structural stability of Cr-doped $\mathrm{Li}_{2} \mathrm{MnSiO}_{4} / \mathrm{C}$ cathode materials by solid-state method, Appl. Surf. Sci., 2018, 433, 1067-1074.

149 X. Wu, S.-X. Zhao, L. Wei, H. Deng and C.-W. Nan, Improving the structure stability and electrochemical performance of $\mathrm{Li}_{2} \mathrm{MnSiO}_{4} / \mathrm{C}$ cathode materials by Tidoping and porous microstructure, J. Alloys Compd., 2018, 735, 1158-1166.

150 S.-N. Lee, S. Baek, S. Amaresh, V. Aravindan, K. Y. Chung, B. W. Cho, W.-S. Yoon and Y.-S. Lee, $\mathrm{Cu}-\mathrm{Li}_{2} \mathrm{MnSiO}_{4}{ }^{-}$ polyaniline composite hybrids as high performance cathode for lithium batteries, J. Alloys Compd., 2015, 630, 292-298.

151 C. Wang, Y. Xu, B. Zhang and X. Ma, Dual-site magnesium doping in $\mathrm{Li}_{2} \mathrm{MnSiO}_{4} / \mathrm{C} / \mathrm{rGO}$ cathode material for lithiumion batteries, Solid State Ionics, 2019, 338, 39-46.

152 W. Liu, Y. Xu and R. Yang, Synthesis, characterization and electrochemical performance of $\mathrm{Li}_{2} \mathrm{MnSiO}_{4} / \mathrm{C}$ cathode material by solid-state reaction, J. Alloys Compd., 2009, 480(2), L1-L4.

153 X. Li, Y. Liu, Z. Xiao, W. Guo and R. Zhang, Ionothermal synthesis and characterization of $\mathrm{Li}_{2} \mathrm{MnSiO}_{4} / \mathrm{C}$ composites as cathode materials for lithium-ion batteries, Ceram. Int., 2014, 40(1, part A), 289-296.

154 R. Liu, J. Chen, Z. Li, Q. Ding, X. An, Y. Pan, Z. Zheng, M. Yang and D. Fu, Preparation of $\mathrm{LiFePO}_{4} / \mathrm{C}$ Cathode Materials via a Green Synthesis Route for Lithium-Ion Battery Applications, Materials, 2018, 11(11), 2251.

155 S. Bolloju, R. Rohan, S.-T. Wu, H.-X. Yen, G. D. Dwivedi, Y. A. Lin and J.-T. Lee, A green and facile approach for hydrothermal synthesis of $\mathrm{LiFePO}_{4}$ using iron metal directly, Electrochim. Acta, 2016, 220, 164-168.

156 W. Liu, Q. Liu, M. Qin, L. Xu and J. Deng, Inexpensive and green synthesis of multi-doped $\mathrm{LiFePO}_{4} / \mathrm{C}$ composites for lithium-ion batteries, Electrochim. Acta, 2017, 257, 82-88.

157 M. Pagliaro and F. Meneguzzo, Lithium battery reusing and recycling: a circular economy insight, Heliyon, 2019, 5(6), e01866.

158 G. Harper, R. Sommerville, E. Kendrick, L. Driscoll, P. Slater, R. Stolkin, A. Walton, P. Christensen, O. Heidrich and S. Lambert, Recycling lithium-ion batteries from electric vehicles, Nature, 2019, 575(7781), 75-86.

159 Y. Shi, G. Chen and Z. Chen, Effective regeneration of $\mathrm{LiCoO}_{2}$ from spent lithium-ion batteries: a direct approach towards high-performance active particles, Green Chem., 2018, 20(4), 851-862.

160 E. A. Aboelazm, G. A. Ali, H. Algarni, H. Yin, Y. L. Zhong and K. F. Chong, Magnetic electrodeposition of the hierarchical cobalt oxide nanostructure from spent lithium-ion batteries: its application as a supercapacitor electrode, $J$. Phys. Chem. C, 2018, 122(23), 12200-12206.

161 Y. I. Mesbah, N. Ahmed, B. A. Ali and N. K. Allam, Recycling of $\mathrm{Li}-\mathrm{Ni}-\mathrm{Mn}-\mathrm{Co}$ Hydroxide from Spent Batteries to Produce High-Performance Supercapacitors with Exceptional Stability, ChemElectroChem, 2020, 7(4), 975982.

162 M. C. A. Gonçalves, E. M. Garcia, H. A. Taroco, H. F. Gorgulho, J. O. Melo, R. R. Silva and A. G. Souza, Chemical recycling of cell phone Li-ion batteries: application in environmental remediation, Waste Manag., 2015, 40, 144-150. 